\title{
Glycoconjugate vaccines against Salmonella enterica serovars and Shigella species: existing and emerging methods for their analysis
}

\author{
Aleksandra Bazhenova $^{1}$ • Fang Gao ${ }^{2}$ - Barbara Bolgiano ${ }^{2}$ (D) Stephen E. Harding ${ }^{1,3}$ (DD
}

Received: 12 November 2020 / Accepted: 25 February 2021 / Published online: 10 April 2021

(C) The Author(s) 2021

\begin{abstract}
The global spread of enteric disease, the increasingly limited options for antimicrobial treatment and the need for effective eradication programs have resulted in an increased demand for glycoconjugate enteric vaccines, made with carbohydrate-based membrane components of the pathogen, and their precise characterisation. A set of physico-chemical and immunological tests are employed for complete vaccine characterisation and to ensure their consistency, potency, safety and stability, following the relevant World Health Organization and Pharmacopoeia guidelines. Variable requirements for analytical methods are linked to conjugate structure, carrier protein nature and size and $O$-acetyl content of polysaccharide. We investigated a key stability-indicating method which measures the percent free saccharide of Salmonella enterica subspecies enterica serovar Typhi capsular polysaccharide, by detergent precipitation, depolymerisation and HPAEC-PAD quantitation. Together with modern computational approaches, a more precise design of glycoconjugates is possible, allowing for improvements in solubility, structural conformation and stability, and immunogenicity of antigens, which may be applicable to a broad spectrum of vaccines. More validation experiments are required to establish the most effective and suitable methods for glycoconjugate analysis to bring uniformity to the existing protocols, although the need for product-specific approaches will apply, especially for the more complex vaccines. An overview of current and emerging analytical approaches for the characterisation of vaccines against Salmonella Typhi and Shigella species is described in this paper. This study should aid the development and licensing of new glycoconjugate vaccines aimed at the prevention of enteric diseases.
\end{abstract}

Keywords Capsular polysaccharide $\cdot$ Enteric fever $\cdot$ HPAEC-PAD $\cdot$ O-Antigen $\cdot$ Typhoid $\cdot$ Vi

Barbara Bolgiano

Barbara.Bolgiano@nibsc.org

Stephen E. Harding

Steve.Harding@nottingham.ac.uk

Aleksandra Bazhenova

Bazhenovaaleksandra@gmail.com

Fang Gao

Fang.Gao@nibsc.org

1 School of Biosciences, University of Nottingham, Sutton Bonington, Loughborough LE12 5RD, UK

2 Division of Bacteriology, National Institute for Biological Standards and Control (NIBSC), Blanche Lane, South Mimms, Potters Bar EN6 3QG, UK

3 Museum of Cultural History, University of Oslo, Postboks 6762 St. Olavs plass, 0130 Oslo, Norway

\section{Introduction}

According to a systematic analysis performed for The Global Burden of Disease Study (GBD) in 2019, the diarrhoeal disease was ranked as the third leading cause of mortality in children and the ninth among all age groups worldwide, contributing to a total of 1.53 million deaths per year (Global Burden of Diseases 2019; Global Burden of Diseases 2019 Risk Factor Collaborators 2020). Bacterial pathogens such as Salmonella subspecies enterica serovar Typhi (S. Typhi), Shigella spp., E. coli and rotavirus account for the largest proportion of deaths from all infectious diseases. The fast emergence of antibiotic resistance observed in bacterial enteric pathogens is of global significance (Humphries and Schuetz 2015; Tribble 2017; Khalil et al. 2018). The Global Antimicrobial Resistance Surveillance System (GLASS) listed these as priority pathogens in 2018 (WHO 2018).

Estimates from The GBD Study suggested that the burden of enteric fevers was around 9.24 million due to $S$. Typhi in 2019 and 14.3 million from $S$. Typhi and $S$. Paratyphi together in 
2017. Of 136,000 deaths, the vast majority of deaths $(86 \%)$ were due to typhoid fever from $S$. Typhi, of which $67 \%$ of deaths occurred in South Asia (Stanaway et al. 2019). Young children and endemic populations for these pathogens in South and Southeast Asia and sub-Saharan Africa are at the most risk. $S$. Paratyphi A results in the most enteric fever cases in Asia, while bacteraemia in children in Africa is mainly caused by $S$. Typhimurium and $S$. Enteritidis (MacLennan et al. 2014). The main risk factors are unsafe water, inadequate hand hygiene and poor sanitation (Global Burden of Diseases 2019; Global Burden of Diseases 2019 Risk Factor Collaborators 2020). High prevalence of the disease in low- and middle-income countries (LMICs), as well as its spread into the wider population highlight the urgent need for effective protection.

In addition to $S$. Typhi and $S$. Paratyphi, other Salmonella enterica serovars are responsible for a high burden of diseasecausing death and morbidity globally ( 0.6 to 3.4 million cases annually, especially among children in sub-Saharan Africa (MacLennan and Steele 2019). The most important etiological agents of invasive nontyphoidal Salmonella (iNTS) disease are $S$. Typhimurium and $S$. Enteritidis. Nontyphoidal Salmonella are responsible for up to $29 \%$ of community-acquired (nonmalarial) bloodstream infections in sub-Saharan Africa with an average case fatality rate of 15-20\% (Reddy et al. 2010; MacLennan and Steele 2019). Also, for these pathogens, the effectiveness of antibiotic treatment is hampered by the difficulty in making a precise diagnosis, the sudden and rapid onset of the disease, and the growing levels of multidrug resistance.

Shigella is the second leading cause of diarrhoeal diseaserelated mortality after rotavirus and a primary cause of mortality in individuals older than 5 years old (Troeger et al. 2018). With an annual burden of 165 million cases mostly in developing countries, shigellosis accounted for 213,000 deaths in all age groups worldwide, $30 \%$ of which were children $<5$ years old (Khalil et al. 2018; WHO 2018). Shigellosis often leads to complications like dysentery that needs antibiotic treatment, which is an emerging challenge due to its resistance. The current WHO recommendations to treat shigellosis include fluoroquinolones as a first line and $\beta$-lactams and cephalosporins as the second line with almost no alternative medicines available (Williams and Berkley 2016; Cohen and Muhsen 2019).

Since capsular polysaccharides and serotype-specific Opolysaccharides are tightly linked with the virulence of enteric pathogenic bacteria, global efforts are being taken to develop vaccine candidates using these antigens to provide long-term antibody-mediated protection from enteric diseases (Cohen and Muhsen 2019). Low immunogenicity of many bacterial glycans can be compensated via carrier protein conjugation that helps to induce a T-cell-dependent response (Rappuoli et al. 2018; Micoli et al. 2018a, b, c; MacCalman et al. 2019; Berti and Micoli 2020). Poor immunogenicity and heterogeneity of bacterial polysaccharides make glycoconjugate vaccine development a challenging but important task, as early successes show. Vaccines can become a rapid solution for the control of enteric disease in both LMICs and highincome countries. To reach the people in need, these vaccines must be licensed in accordance with WHO recommendations, national or regional pharmacopoeias and specific approvals issued by the National Regulatory Authorities (NRAs). From the early development stage, the identity, purity, physico-chemistry, stability, composition, size, efficacy and safety profiles of glycoconjugate vaccines must be analysed and meet standards set by the NRA (Ravenscroft et al. 2015b). The global prevalence of these enteric pathogens and the unmet need for effective and accessible vaccines reflect the demand for more rapid and precise characterisation methods that would provide superior quality control in line with existing regulations. This paper reviews current and emerging approaches to vaccine design and analytical methods aiding development and quality control of glycoconjugate vaccines based on Vi capsular polysaccharide of $S$. Typhi and lipopolysaccharide O-antigen $(\mathrm{O}-\mathrm{Ag})$ polysaccharide of Shigella spp.

\section{Part I}

\section{S. Typhi and Shigella spp.: strain diversity and pathogenesis}

S. Typhi and S. Paratyphi and Shigella spp. are Gram-negative bacteria, which are responsible for typhoid/paratyphoid fevers and shigellosis, respectively (Riddle et al. 2018). At a relatively low dosage, these pathogens also can cause asymptomatic infections, with Salmonella being capable to infect starting at about $10^{5}-10^{8}$ organisms and Shigella spp. with a load of only 10 bacteria (Puzari et al. 2018; Liu et al. 2016). Salmonella enterica serovars Typhi and Paratyphi A (rarely B or C) are the main cause of disease. In contrast, shigellosis can be caused by representatives of the Shigella family, which is subdivided into four groups (Cohen et al. 2019). Within each defined group, multiple serotypes exist (Table 1). Up to $90 \%$ of the shigellosis cases are caused by the $S$. flexneri and S. sonnei serotypes (Page et al. 2016; Kotloff et al. 2018). $S$. flexneri is mostly endemic in LMICs, while $S$. sonnei tends to be present in developed countries, where it overrides other serotypes. The enhanced ability of $S$. sonnei to develop resistance to broad-spectrum antimicrobials makes it an important target pathogen, especially in developed countries, where it has started to become more prevalent. This serotype can accept horizontally transferred DNA and maintain it with better stability than $S$. flexneri, which results in a growing dominance. DNA transfer results in O-antigen switching, and Oantigens are the main immunogens in vaccines (Anderson et al. 2016; Thompson et al. 2015; Das and Mandal 2019).

Complications of the infection include intestinal immunosuppression that may overpower the established immunity to 
Table 1 Currently known serotypes of Shigella spp.

\begin{tabular}{lll}
\hline Shigella species & Known serotypes & Newly identified serotypes \\
\hline Shigella dysenteriae & $1-15$ & - \\
Shigella flexneri & $1 \mathrm{a}, 1 \mathrm{~b}, 1 \mathrm{~d}, 2 \mathrm{a}, 2 \mathrm{~b}, 3 \mathrm{a}, 3 \mathrm{~b}, 4 \mathrm{a}, 4 \mathrm{av}, 4 \mathrm{~b}, 5 \mathrm{a}, 5 \mathrm{~b}, 6, \mathrm{X}, \mathrm{Y}$ & $\mathrm{Xv}, \mathrm{Yv}, 7 \mathrm{a}, 7 \mathrm{~b}$ \\
Shigella boydii & $1-19$ & - \\
Shigella sonnei & 1 & - \\
\hline
\end{tabular}

Adapted from Muthuirulandi Sethuvel et al. (2016)
Shigella giving rise to repeat infections (Brunner et al. 2019). Diversity among pathogenic serotypes, high infectious capacity, variations among clinically relevant strains especially within the $S$. flexneri family, and disease seasonality and geographic distribution and prevalence complicate the development of an effective vaccine (Muthuirulandi Sethuvel et al. 2016; Knirel et al. 2015; Barel and Mulard 2019; Das and Mandal 2019).

\section{Antibiotic resistance}

Recent reports alert on rising extensive drug resistance (XDR) in $S$. Typhi to common antimicrobial agents, such as cotrimoxazole, ampicillin, chloramphenicol and trimethoprimsulfamethoxazole, fluoroquinolones and third-generation cephalosporins (Klemm et al. 2018). In endemic populations with high prevalence of XDR Salmonella, not many alternative treatments exist apart from azithromycin and carbapenems (Klemm et al. 2018). But today, bacteria are still capable of developing resistance to azithromycin when used as a second-line agent (Ahsan and Rahman 2019). Emerging advantageous genetic mutations for pathogen survival and ciprofloxacin resistance (recommended as first-line treatment) were recently reported by Pathogenwatch. With increasingly limited treatment options for $S$. Typhi, control strategies like vaccination and hygiene maintenance must be established (Argimón et al. 2020).

In Shigella, multiple studies have found rising resistance to ciprofloxacin, and quinolones, especially among isolates from children (WHO 2005; Williams and Berkley 2018). Moreover, in 2014, WHO published a detailed report on the geographical burden of fluoroquinolone resistance among Shigella isolates, which showed worrying rates especially for the South-East Asia region which accounts as one of the endemic regions for shigellosis (Table 2) (WHO 2014a). A retrospective review showed that multidrug resistance among Shigella isolates varies from 36-98\% (Muthuirulandi Sethuvel et al. 2016). Despite this, some of these antibiotics remain in the official guidelines globally (Table 3 ). The Infectious Diseases Society of America (IDSA) strongly recommended precise diagnostic tests and strict adherence to public health policies when working with patients suffering from enteric infections in high transmission risk areas and advised cautious prescription of antimicrobial agents (Shane et al. 2017). For example, the WHO recommendations for treatment of dysentery had minimal alterations from 2005 to 2013 and feature ciprofloxacin as the first-line antibiotic and pivmecillinam, ceftriaxone and azithromycin as second-line options. Note that pivmecillinam has no paediatric formulation and azithromycin is not recommended for paediatric treatment, while ceftriaxone is recommended for injection in children and not adults (WHO 2005).

\section{Polysaccharides as target antigens}

\section{Salmonella Typhi capsule}

Pathogenic bacteria often produce extracellular polysaccharide capsules that serves as virulence factors in promoting attachment and colonisation and in protecting the bacteria from opsonisation, complement binding and opsonophagocytosis, as well as providing hydration and transport functions. The Vi capsular polysaccharide of $S$. Typhi is immunogenic and is represented by non-stoichiometrically $O$-acetylated $\alpha-1,4$ linked $N$-acetylgalactosaminuronic acid residues and is crucial for host infection, making it a major vaccine target (Liston et al. 2016). The effectiveness of $\mathrm{Vi}$ as an immunogen has been an important research topic that led to a promising route to a safer and more protective vaccine design (Robbins and Robbins 1984).

\section{Variability of O-antigen targets in Vi-negative Salmonella and Shigella}

Not all enteric Salmonella contain a capsular polysaccharide, leaving the bacterial cell surface-exposed O-Ag as a promising vaccine target. In common with other Gram-negative organisms, the cell envelope of Salmonella and Shigella contains a lipopolysaccharide (LPS) complex. This consists of an outer O-polysaccharide coat, a middle portion (the R core) and an inner hydrophobic lipid A chain. The LPS moiety may function as an endotoxin and $\mathrm{O}$-polysaccharide repeating units confer O-Ag specificity and virulence (Whitfield et al. 2020). For example, rough serotypes of Salmonella and Shigella spp. with incomplete or no surface O-polysaccharide are usually avirulent or attenuated compared to the smooth serotypes which have a complete O-Ag moiety. S. Typhi serovars are positive for LPS O9 and $\mathrm{O} 12$ antigens and Vi capsular 
Table 2 Collated data on Salmonella and Shigella fluoroquinolones resistance

\begin{tabular}{|c|c|c|}
\hline \multirow[t]{2}{*}{$\begin{array}{l}\text { Reporting region (data } \\
\text { based on }>30 \text { tested isolates) }\end{array}$} & \multicolumn{2}{|c|}{$\begin{array}{l}\text { Range of resistant proportion in } \\
\text { isolates }(\%)\end{array}$} \\
\hline & Nontyphoidal Salmonella & Shigella \\
\hline \multicolumn{3}{|l|}{ African region } \\
\hline - National data & $0-35$ & $0-3$ \\
\hline - Publications & $0-30$ & $0-9$ \\
\hline \multicolumn{3}{|l|}{ Region of Americas } \\
\hline - National data & $0-96$ & $0-8$ \\
\hline - Publications & 0 & $0-20$ \\
\hline \multicolumn{3}{|l|}{ Eastern Mediterranean } \\
\hline \multicolumn{3}{|l|}{ Region } \\
\hline - National data & $2-49$ & $3-10$ \\
\hline - Publications & $0-46$ & $0-41.3$ \\
\hline \multicolumn{3}{|l|}{ European Region } \\
\hline - National data and reports to & $2-3$ & $0-47$ \\
\hline \multicolumn{3}{|l|}{ FWD-Net } \\
\hline - Publications & 13 & 0 \\
\hline \multicolumn{3}{|l|}{ South-East Asia Region } \\
\hline - National data & $0.2-4$ & \\
\hline - Publications & 1.4 & $0-82$ \\
\hline \multicolumn{3}{|l|}{ Western Pacific Region } \\
\hline - National data & $0-14$ & $3-28$ \\
\hline - Network/institution data & $0-0.3$ & 0 \\
\hline - Publications & & 2 \\
\hline
\end{tabular}

Adapted from the World Health Organization Antimicrobial Resistance Global Report on Surveillance (2014a). FWD-Net, Foodborne and Waterborne Diseases and Zoonoses Network

polysaccharide (Crump et al. 2015). But, $S$. Typhi may have a Vi-negative serotype, so O-Ag protein conjugation approaches may need to be applied (Salman et al. 2017).

Non-typhoidal Salmonella are the representatives of non-encapsulated enteric pathogens that contain LPS as an outer membrane component. While lipid A is an exceedingly conserved element among Gram-negative bacteria, which is responsible for toxicity, the nature and structures of the repeating glycans in the O-antigen chain are often serotype specific and important for pathogenicity. The $\mathrm{R}$ core has a proximal inner region composed of heptose residues, where phosphate, phosphorylethanolamine or pyrophosphorylethanolamine groups are often contained as substitutions; the outer core is usually built of neutral or amino hexoses (Whitfield et al. 2020). In glycoconjugate vaccines against iNTS, the core and O-Ag portions of the LPS are used to induce a protective response. Recently, flagellin proteins native to iNTS serovars were tested in the role of secondary antigens and shown to be a promising approach for the development of a highly potent vaccine (Baliban et al. 2018; Baliban et al. 2020).
Shigella spp. do not possess a capsular component but all contain LPS anchored to the outer membrane via lipid A. Antigenic O-polysaccharide chains attached at the distal end of the LPS core define the serotype affiliation and straindependent immune specificity of Shigella. The length and structural availability of this O-Ag play a key role in pathogenesis and host resistance (Lindberg et al. 1991; Caboni et al. 2015). The O-Ag is unique for each serotype, reflecting the genetic diversity of Shigella spp. (Perepelov et al. 2012).

\section{Part II}

\section{Vaccines on the market and in the pipeline}

In the 1960 s, the first live-attenuated $S$. Typhi vaccine was created and gave up to 7 years of protection (Ashcroft et al. 1967). Nevertheless, systemic adverse events following the use of such vaccines excluded them from modern treatment approaches (Ashcroft et al. 1964). Today, efforts are taken in the direction of native and synthetic polysaccharide formulations, protein-conjugated antigens, combination vaccines and alternative delivery systems like GMMA (generalised modules for membrane antigens) (Rossi et al. 2014). Four Vi conjugate vaccines have been licensed with one so far receiving WHO prequalification. Vi-DT (diphtheria toxoid) and others are in late-stage development or waiting for approval. There are several Vi PS based and a number of bivalent conjugate vaccines against Typhi and Paratyphi in development. Examples can be seen in Table 4.

Salmonella Typhimurium and $S$. Enteritidis bivalent vaccine could represent a valuable public health intervention. Two approaches, both O-Ag based, have been evaluated. The first approach is based on glycoconjugation, where $S$. Typhimurium and $S$. Enteritidis O-Ag are independently linked to $\mathrm{CRM}_{197}$ or a homologous flagellin protein as carriers. The second approach is represented by the development of a bivalent formulation of $S$. Typhimurium and $S$. Enteritidis genetically modified outer membrane vesicles (OMV) termed "GMMA" (Micoli et al. 2018a, b, c). Several glycoconjugates are now in preclinical development for iNTS, and some employ flagellin from $S$. Enteritidis to function as both a carrier protein for bacterial O-Ag and a secondary antigen in an attempt to increase the efficacy. This preparation is scalable and allows bivalent/multivalent formulations for different O-PS antigens. This conjugation strategy may contribute to an enhanced immunogenicity and safety of this potential vaccine candidate and is likely to come at a lower production cost, which is important for implementation in LMICs (MacLennan and Steele 2019; Baliban et al. 2020).

With over 50 serotypes of Shigella arising from O-Ag variations, the development of an appropriate target for a vaccine is challenging. Antigen variability complicates the protection 


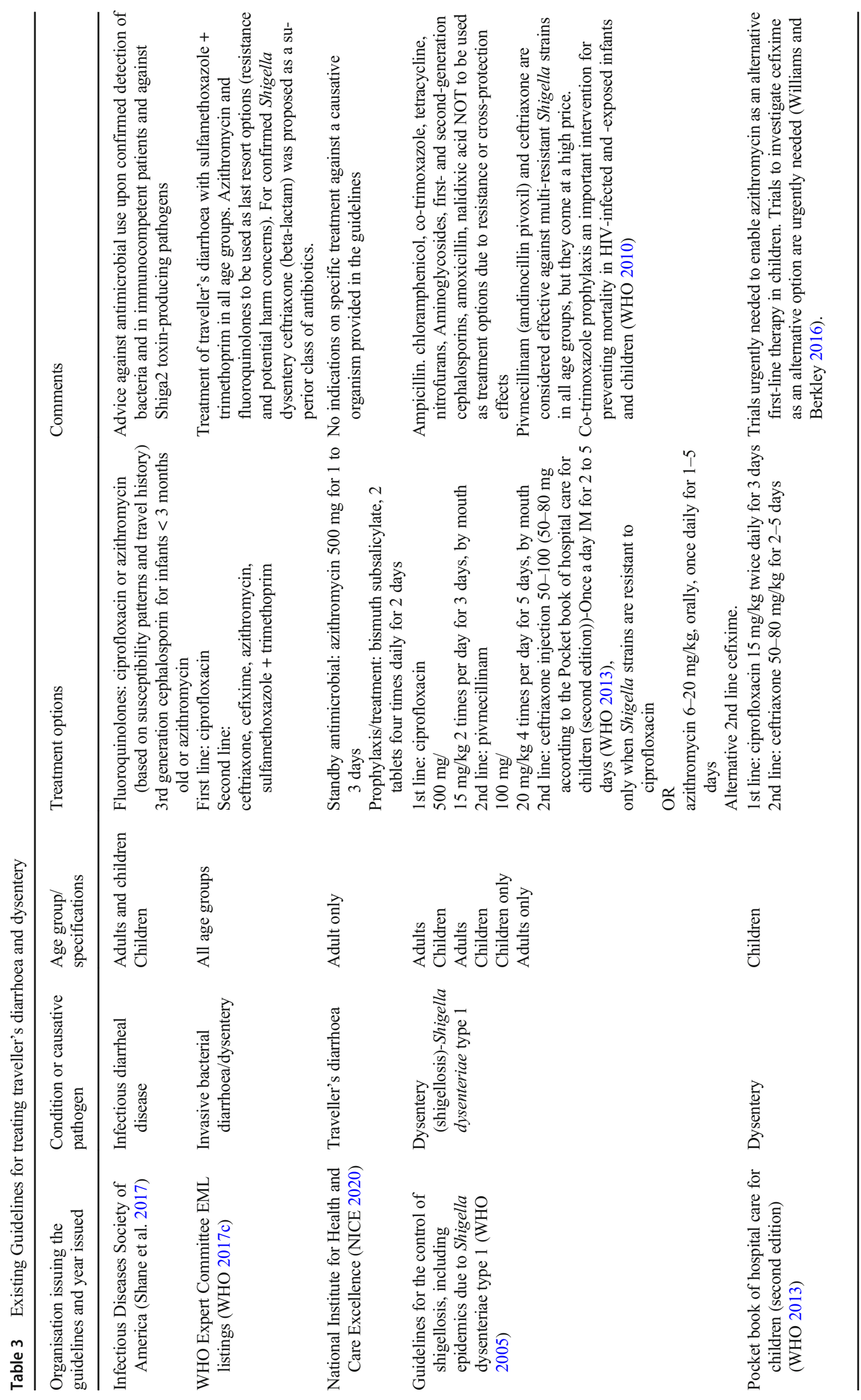


Table 4 Typhoid and paratyphoid vaccines landscape: licensed and in clinical trials

\begin{tabular}{|c|c|c|c|}
\hline Disease & Vaccine name/construct & Manufacturer & Status \\
\hline Typhoid & $\begin{array}{l}\text { Typbar-TCV/glycoconjugate } \\
\text { Vi-TT }\end{array}$ & Bharat Biotech India Ltd, Hyderabad & $\begin{array}{l}\text { Licensed in India, Nepal, Nigeria } \\
\text { Licensed, and prequalified by WHO in Dec } 2017 \\
\text { for UNICEF procurement (Jin et al. 2017) }\end{array}$ \\
\hline Typhoid & PedaTyph/glycoconjugate Vi-TT & Bio-Med Pvt. Ltd, India & Licensure in India (Syed et al. 2020) \\
\hline Typhoid & $\begin{array}{l}\text { ZyVAC-TCV/glycoconjugate } \\
\text { Vi-TT }\end{array}$ & Cadila Healthcare Limited, India & $\begin{array}{l}\text { Licensed in India } \\
\text { Launched for Typhoid (in adult volunteers) in India } \\
\quad \text { Adisinsight.springer.com } 2020 \mathrm{a}, \mathrm{b} \text { ) } \\
\text { WHO prequalification will be sought }\end{array}$ \\
\hline Typhoid & Glycoconjugate Vi-TT & Walvax & $\begin{array}{l}\text { Licensed in India in } 2020 \text { (Steele et al. 2020) } \\
\text { Preclinical (Khan et al. 2017) }\end{array}$ \\
\hline Typhoid & $\begin{array}{l}\text { TYPHIBEV/glycoconjugate } \\
\text { Vi-CRM }_{197}\end{array}$ & $\begin{array}{l}\text { Biological E Ltd, India/GVGH (GSK) } \\
\text { Technology Transfer Agreement } \\
\text { (TTA) }\end{array}$ & WHO prequalification obtained in Dec 2020 \\
\hline \multirow[t]{3}{*}{ Typhoid } & \multirow[t]{3}{*}{ Glycoconjugate Vi-DT } & $\begin{array}{l}\text { SK Bioscience } \\
\text { The International Vaccine Institute (IVI } \\
\text { TTA) }\end{array}$ & $\begin{array}{l}\text { Phase II completed, enrolling into phase III (Steele } \\
\text { et al. 2020) }\end{array}$ \\
\hline & & PT Bio Farma (IVI TTA) & $\begin{array}{l}\text { Phase-III clinical trials in typhoid (in adolescents, in } \\
\text { children, in infants, prevention, in adults) in } \\
\text { Indonesia (IM) } \\
\text { ClinicalTrials.gov Identifier: NCT04051268 }\end{array}$ \\
\hline & & Incepta (IVI TTA) & Preclinical (Adisinsight.springer.com 2020a, b) \\
\hline Typhoid & Glycoconjugate Vi-TT & Eubiologics, Korea & Phase 1 (Syed et al. 2020) \\
\hline Typhoid & Glycoconjugate Vi-DT & DAVAC/Finlay Institute, Vietnam & Preclinical (Syed et al. 2020) \\
\hline Typhoid & Glycoconjugate Vi-PspA & IVI & Preclinical (Kothari et al. 2014) \\
\hline Typhoid & Typhim Vi/Vi PS & Sanofi Pasteur SA & $\begin{array}{l}\text { Prequalified by the WHO (WHO prequalified } \\
\text { vaccines list) }\end{array}$ \\
\hline Typhoid & Typherix/Vi PS & GSK & $\begin{array}{l}\text { Discontinued due to better alternatives available and } \\
\text { manufacturing struggles in } 2018 \text { (GSK 2018) }\end{array}$ \\
\hline Typhoid & Ty21a (Vivotif)/live attenuated & PaxVax & $\begin{array}{l}\text { Prequalified by the WHO (Sahastrabuddhe and } \\
\text { Saluja 2019) }\end{array}$ \\
\hline $\begin{array}{l}\text { Paratyphi A and } \\
\text { Typhoid }\end{array}$ & $\begin{array}{l}\text { Glycoconjugate } \mathrm{O}: 2,12-\mathrm{TT}+ \\
\text { Vi-TT }\end{array}$ & NIH, Lanzhou & Phase II (Martin et al. 2016) \\
\hline $\begin{array}{l}\text { Paratyphi A and } \\
\text { Typhoid }\end{array}$ & $\begin{array}{l}\text { Glycoconjugate O:2,12-CRM } \\
+ \text { + Vi-CRM } \\
197\end{array}$ & GVGH, Biological E & Preclinical (Martin et al. 2016) \\
\hline Paratyphi A & $\begin{array}{l}\text { Glycoconjugate CVD } 1902+ \\
\text { CVD } 909 / \text { mutations in guaBA } \\
\text { and } \operatorname{clp} X\end{array}$ & $\begin{array}{l}\text { University of Maryland Baltimore } \\
\text { (UMB), Bharat Biotech }\end{array}$ & Phase I (Martin et al. 2016) \\
\hline Paratyphi A & $\begin{array}{l}\text { Glycoconjugate } \mathrm{O}: 2,12-\mathrm{DT}+ \\
\text { Vi-DT }\end{array}$ & IVI & Preclinical (Martin et al. 2016) \\
\hline iNTS & $\begin{array}{l}\text { Trivalent glucoconjugate } \\
\text { (S. typhimurium COPS:FliC+ } \\
\text { TypbarTCV) }\end{array}$ & $\begin{array}{l}\text { UMSOM-CVD, Bharat Biotech } \\
\text { (Hyderabad, India }\end{array}$ & $\begin{array}{l}\text { Preclinical, planned to roll into phase } 1 / 2 \text { (Baliban } \\
\text { et al. 2020) }\end{array}$ \\
\hline iNTS & $\begin{array}{l}\text { S. typhimurium LH1160 ( } \Delta \text { purB } \\
+\Delta \text { phoP/Q) live-attenuated } \\
\text { vaccine }\end{array}$ & Massachusetts General Hospital, Boston & $\begin{array}{l}\text { Phase } 1 \text { (Angelakopoulos and Hohmann 2000). Not } \\
\text { followed up due to weak response }\end{array}$ \\
\hline iNTS & $\begin{array}{l}\text { S. typhimurium WT05 }(\Delta \text { aro } C+ \\
\Delta s s a V) \text { live-attenuated vaccine }\end{array}$ & Microscience & Phase 1 (Hindle et al. 2002) \\
\hline iNTS & $\begin{array}{l}\text { GMMA (S. typhimurium and } \\
\text { S. enteritidis) }\end{array}$ & $\begin{array}{l}\text { GSK Vaccines Institute for Global } \\
\text { Health S.r.l, Siena, Italy }\end{array}$ & Preclinical (Baliban et al. 2020) \\
\hline iNTS & $\begin{array}{l}\text { S. enteritidis and } S . \text { typhimurium } \\
\text { COPS:FliC glycoconjugates }\end{array}$ & $\begin{array}{l}\text { CVD at the University of Maryland } \\
\text { School of Medicine, Baltimore, } \\
\text { Maryland USA }\end{array}$ & Preclinical (Baliban et al. 2018) \\
\hline iNTS & GMMA & GVGH & Preclinical (Martin et al. 2016) \\
\hline
\end{tabular}


of the population in non-endemic areas. Thus, a vaccine should preferably be multivalent covering the most pathogenic Shigella species such as S. flexneri 1b, 2a, 3a and 6 , and $S$. sonnei according to the WHO, and a recent meta-study on antibiotic resistance (Mani et al. 2016; Das and Mandal 2019; Micoli et al. 2018a, b, c; Raso et al. 2020; WHO 2018, 2020a). The global enteric multi-centre study suggests that such a multivalent formulation would cover $72 \%$ of Shigella strains protecting directly and cross-protect for up to $89 \%$ of all strains (Livio et al. 2014). Shigella dysenteriae type 1 used to be linked to rapid spread and high mortality rates; however, no epidemic cases were reported in the last 20 years and it is rarely included in serotype-specific vaccines (Kotloff et al. 2018). Several vaccines have now been developed with a few entering phase III clinical trials: most candidates are based on $S$. flexneri 2a LPS conjugates (Table 5). Although Shigella vaccines lack WHO guidelines for vaccine development, a recent draft version suggests that quality and safety must be monitored at least to the standard of currently licensed glycoconjugate vaccines (WHO 2020a, b). New standards for Shigella are also going to be established soon to aid the development of a vaccine evaluation protocol (NIBSC 2020).

\section{Factors that play a role in immunogenicity for Vi and Shigella 0-Ag glycoconjugates}

\section{Antigen chemistry and $\mathrm{O}$-acetyl content and modifications}

The structural implications of glycan antigens to become an efficient immunogen are still unclear. Apart from carbohydrate chain length, other important viability properties affect the resultant antigen success: the stereochemistry of glycosidic linkages, glycan position within a repeating unit, locations of branching points and biochemical composition, which complicate design and analysis. Size/span of the epitope, terminal glycan residues, presence/absence of branching points, substituent groups, such as $O$-acetyl, and number of repeating units may be considered as key parameters to measure (Anish et al. 2014; Berti et al. 2018). Table 6 lists the repeating unit structures of $S$. Typhi capsular polysaccharide and the Oantigens of vaccine-relevant Salmonella and Shigella species.

For Vi PS, $O$-acetylation is a major factor for immune potency (Szu et al. 1991; Hitri et al. 2019). Vi PS is variably $O$-acetylated at the carbon 3 of the repeating monosaccharide. The $O$-acetyl groups are the most solvent exposed (Szu et al. 1991; Hitri et al. 2019) and the primary epitope exposed for antibody binding since carboxyl and $N$-acetyl groups are buried within the PS helix, making them less available as antibody targets, which are only be exposed in de- $O$-acetylated Vi (Hitri et al. 2019). Antibodies reacting with carboxyl and/or $\mathrm{N}$-acetyl groups in de- $\mathrm{O}$-acetylated $\mathrm{Vi}$ have been reported, but these groups are unlikely to be dominant in $\mathrm{Vi}$ vaccines, which meet the recommended level of $O$-acetylation (Qadri et al. 1990; Szu et al. 1991). The relatively high viscosity of Vi makes it more challenging to characterise with physicochemical methods like HPLC-SEC or matrix-based sample separation methods, for example ultrafiltration membranes or solidphase extraction cartridges in a free polysaccharide assay (Hitri et al. 2019). Partially, $O$-acetylated PS may be structurally beneficial in a formulation to give access to additional epitope(s) (Hitri et al. 2019). Nevertheless, the key to an effective $\mathrm{Vi}$ vaccine is to ensure that the $O$-acetyl content will be at least $52 \%$ or $2.0 \mathrm{mmol} / \mathrm{g}$ of PS as specified by WHO recommendations (Szu et al. 1991; Lemercinier et al. 2000; WHO 2014b).

With iNTS and Shigella, the level and position of $O$-acetylation of the O-Ag and any chemical modifications of the LPS in the infectious strains mediate the strength of the immune response and are considered to be important variables for vaccine safety and efficacy (Kubler-Kielb et al. 2007; Giardina et al. 2005). The O-polysaccharide portion of the LPS is the most exposed and is extremely diverse in chain length, chain distribution and composition, which all affect virulence (Carter et al. 2007; Morona et al. 2003; West 2005). The O-Ag can be composed of multiple repeating units (RUs), which contain two to six monosaccharides per RU and are heterogeneously distributed on the LPS molecule. The chain numbers and lengths are serotype dependent (Barel and Mulard 2019). Techniques currently used for characterisation of LPS and O-Ag in vaccine preparations are 1D and 2D NMR, GC, GC-MS and HPAECPAD (Micoli et al. 2014; Gerke et al. 2015; De Benedetto et al. 2017a; Raso et al. 2020).

\section{Carrier proteins and conjugation chemistry}

To confer immunogenicity, the saccharide component is chemically or biologically conjugated to a carrier protein. Currently licensed carriers of Vi PS include tetanus toxoid (TT), diphtheria toxoid (DT) and cross reacting material 197 $\left(\mathrm{CRM}_{197}\right)$, while other glycoconjugates utilise Haemophilus protein $\mathrm{D}$ and outer membrane protein complex from serogroup B meningococcus and pneumococcal proteins. The recombinant non-toxic form of Pseudomonas aeruginosa exotoxin A ( $r$ EPA) has been evaluated as a carrier protein with Shigella antigens and Vi PS (Cohen et al. 1997; Kubler-Kielb et al. 2007; Thiem et al. 2011; Kämpf et al. 2015). Most emerging protein carriers are recombinant, and alternatives such as OMV, GMMA, inorganic nanoparticles and viruslike particles are being investigated. The GMMA approach may be promising for vaccine development in LMICs if it is cheaper to produce and its efficacy meets accepted standards. More methods like one-pot (single reaction mixture) and chemo-enzymatic protocols, along with HPLC-based automated oligosaccharide construction methods and advances in 
Table 5 Vaccines against Shigella spp.: current landscape

\begin{tabular}{|c|c|c|c|}
\hline Disease & Vaccine name/construct & Developer & Status \\
\hline Shigella dysenteriae & Bioconjugate vaccine Sd1-EPA (GVXN SD133) & $\begin{array}{l}\text { LimmaTech Biologics AG (Former } \\
\text { GlycoVaxyn AG) Schlieren, } \\
\text { Switzerland }\end{array}$ & $\begin{array}{l}\text { Phase } 1 \\
\text { ClinicalTrials.gov Identifier: } \\
\text { NCT01069471 }\end{array}$ \\
\hline S. flexneri $2 \mathrm{a}$ & 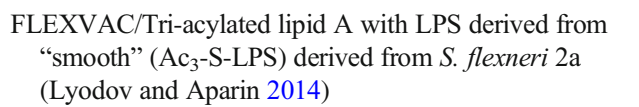 & Gritvac, Moscow, Russia & $\begin{array}{l}\text { Phase III ongoing } \\
\text { Clinical study no. } 161 \\
\text { (Rosminzdrav 2020) }\end{array}$ \\
\hline S. flexneri $2 \mathrm{a}$ & $\begin{array}{l}\text { Live-attenuated } \Delta \text { guaBA }+\Delta \text { set }, \Delta \text { sen }(C V D 1208 s) \\
\quad(\text { Toapanta et al. 2018) }\end{array}$ & $\begin{array}{l}\text { CVD at the University of Maryland } \\
\text { School of Medicine, Baltimore, } \\
\text { Maryland USA, PATH }\end{array}$ & $\begin{array}{l}\text { Phase } 2 \\
\text { ClinicalTrials.gov Identifier: } \\
\quad \text { NCT01531530 }\end{array}$ \\
\hline S. flexneri $2 \mathrm{a}$ & $\begin{array}{l}\text { Flexyn2a/recombinant O-PS glycoconjugate } S \text {. flexneri } \\
\text { 2a-EPA bioconjugate vaccine }\end{array}$ & $\begin{array}{l}\text { LimmaTech Biologics AG Schlieren, } \\
\text { Switzerland (Kämpf et al. 2015) }\end{array}$ & $\begin{array}{l}\text { Phase } 2 \mathrm{~b} \\
\text { ClinicalTrials.gov Identifier: } \\
\text { NCT02646371 }\end{array}$ \\
\hline S. flexneri $2 \mathrm{a}$ & $\begin{array}{l}\text { Artificially combined Invaplex } x_{\mathrm{AR}} / \text { intranasal } \\
\text { macromolecular complex (LPS + IpaC + IpaD proteins) }\end{array}$ & $\begin{array}{l}\text { PATH and WRAIR, Silver Spring, } \\
\text { Maryland }\end{array}$ & $\begin{array}{l}\text { Phase } 1 / 2 \mathrm{~b} \\
\text { ClinicalTrials.gov Identifier: } \\
\text { NCT02445963 } \\
\text { Plans to collaborate with } \\
\text { Enesi Pharma to deliver } \\
\text { vaccine needle-free }\end{array}$ \\
\hline S. flexneri $2 \mathrm{a}$ & $\begin{array}{l}\text { Invaplex }_{\text {DETOX }} \text { IM (Detoxified LPS + IpaC + IpaD } \\
\text { proteins) }\end{array}$ & $\begin{array}{l}\text { PATH, DFID and WRAIR, Silver } \\
\text { Spring, Maryland }\end{array}$ & $\begin{array}{l}\text { Phase } 1 \text { completed } \\
\text { ClinicalTrials.gov Identifier: } \\
\text { NCT } 03869333\end{array}$ \\
\hline S. flexneri $2 \mathrm{a}$ & S. flexneri 2a-TT15 synthetic O-PS based conjugate & Institut Pasteur, Paris, France & $\begin{array}{l}\text { Phase } 1 \\
\text { ClinicalTrials.gov Identifier: } \\
\text { NCT02797236 }\end{array}$ \\
\hline S. flexneri $2 \mathrm{a}$ & $\begin{array}{l}\text { DB fusion subunit candidate/Ipa proteins (IpaB and IpaD) } \\
\text { of Shigella (Martinez-Becerra et al. 2013) }\end{array}$ & PATH, Washington, DC & Preclinical \\
\hline S. flexneri $2 \mathrm{a}$ & $\begin{array}{l}\text { Trivalent killed whole-cell Shigella vaccine (Kaminski } \\
\text { et al. 2014) }\end{array}$ & WRAIR, PATH & Preclinical \\
\hline S. flexneri $2 \mathrm{a}$ & $\begin{array}{l}\text { OMV with heat-inactivated (HT- } \Delta \text { tolR) mutation (Pastor } \\
\text { et al. 2018) }\end{array}$ & University of Navarra, Navarra, Spain & Preclinical \\
\hline S. flexneri $2 \mathrm{a}$ and $S$. sonnei & Oral live F 2a-sonnei (FS) vaccine & China & Licensed (Wang 2003) \\
\hline S. flexneri $2 \mathrm{a}+$ S. sonnei & $\begin{array}{l}\text { O-PS-rEPA chemical conjugates (monovalent formulation } \\
\text { for each strain) }\end{array}$ & $\begin{array}{l}\text { NICHHD (National Institute of Child } \\
\text { Health and Human Development), } \\
\text { USA }\end{array}$ & $\begin{array}{l}\text { Phase } 3 \\
\text { ClinicalTrials.gov Identifier: } \\
\text { NCT00368316 }\end{array}$ \\
\hline $\begin{array}{l}\text { S. flexneri } 2 \text { a and } S \text {. sonnei } \\
\text { (potential } \\
\text { cross-protection) }\end{array}$ & $\begin{array}{l}\text { Killed whole-cell/O-antigen polymerase mutant, truncated } \\
\text { Shigella (Kim et al. 2018) }\end{array}$ & $\begin{array}{l}\text { International Vaccine Institute, Seoul, } \\
\text { Korea and PATH }\end{array}$ & $\begin{array}{l}\text { Preclinical. Plan to move into } \\
\mathrm{Ph} 1 / 2 \mathrm{~b} \text { trials }\end{array}$ \\
\hline $\begin{array}{l}\text { S. flexneri } 2 \mathrm{a} \text { and } 3 \mathrm{a} \text { and } \\
\text { S. sonnei }\end{array}$ & $\begin{array}{l}\text { CombiVax/live, genetically attenuated typhoid Ty21a } \\
\text { with biosynthetic Shigella sonnei O-Ag gene insertion } \\
\text { (Dharmasena et al. 2016) }\end{array}$ & $\begin{array}{l}\text { Protein Potential LLC, Rockville, } \\
\text { Maryland USA }\end{array}$ & Preclinical \\
\hline $\begin{array}{l}\text { Four most epidem. relevant } \\
\text { strains } \\
\text { (cross-protection)/no } \\
\text { details }\end{array}$ & $\begin{array}{l}\text { Tetravalent Shigella bioconjugate containing four different } \\
\text { O-Ag }\end{array}$ & $\begin{array}{l}\text { LimmaTech Biologics AG Schlieren, } \\
\text { Switzerland/GSK Vaccines Institute } \\
\text { for Global Health }\end{array}$ & $\begin{array}{l}\text { Phase } 1 / 2 \\
\text { ClinicalTrials.gov Identifier: } \\
\text { NCT04056117 }\end{array}$ \\
\hline S. sonnei & $\begin{array}{l}\text { Live-attenuated vaccines: (WRSS1 }(\Delta \text { virG); (WRSs2 } \\
\quad(\Delta \text { virG }+\Delta \text { set, } \Delta \text { sen }) \text {; WRss } 3(\Delta \text { virG }+\Delta \text { set, } \Delta \text { sen, } \\
\quad \Delta \mathrm{msbB})\end{array}$ & $\begin{array}{l}\text { Walter Reed Army Institute of Research } \\
\text { (WRAIR), Silver Spring, Maryland }\end{array}$ & $\begin{array}{l}\text { Phase } 2 \mathrm{~b} \text { (WRSs } 2 \text { /NIAID) } \\
\text { ClinicalTrials.gov Identifier: } \\
\text { NCT04242264 }\end{array}$ \\
\hline S. sonnei & $\begin{array}{l}\text { 4-component GMMA-based 1790GAHB vaccine (Rossi } \\
\text { et al. 2014) }\end{array}$ & $\begin{array}{l}\text { GSK Vaccines Institute for Global } \\
\text { Health S.r.l, Siena, Italy }\end{array}$ & Phase 2 \\
\hline
\end{tabular}

the assembly of synthetic glycan and alternative nanocarriers that are being developed will speed up vaccine development (Safari et al. 2012; Micoli et al. 2018a, b, c; Wen et al. 2018). Such new protocols will also require characterisation, consistency of production and verification of their quality and safety by currently recommended assays.

Glycoconjugate vaccines are produced by either chemical, bioconjugation or GMMA approach, conferring variations in conjugation chemistries that affect the ability to properly define and standardise a molecule. For example, chemical conjugation protocols expose or modify each oligo- or poly-saccharide separately; a similar situation is seen in "sun-type" bioconjugate vaccines with a single point of conjugation. "Lattice-type" conjugates where carrier protein and $\mathrm{O}$-antigens interlink several times may be more challenging to analyse (Barel and Mulard 2019). The integrity of protective saccharide epitopes should be verified following modifications. 
Table 6 Structures of the repeating units of capsular polysaccharide and serotypespecific O-Antigens of Salmonella serovars and Shigella species

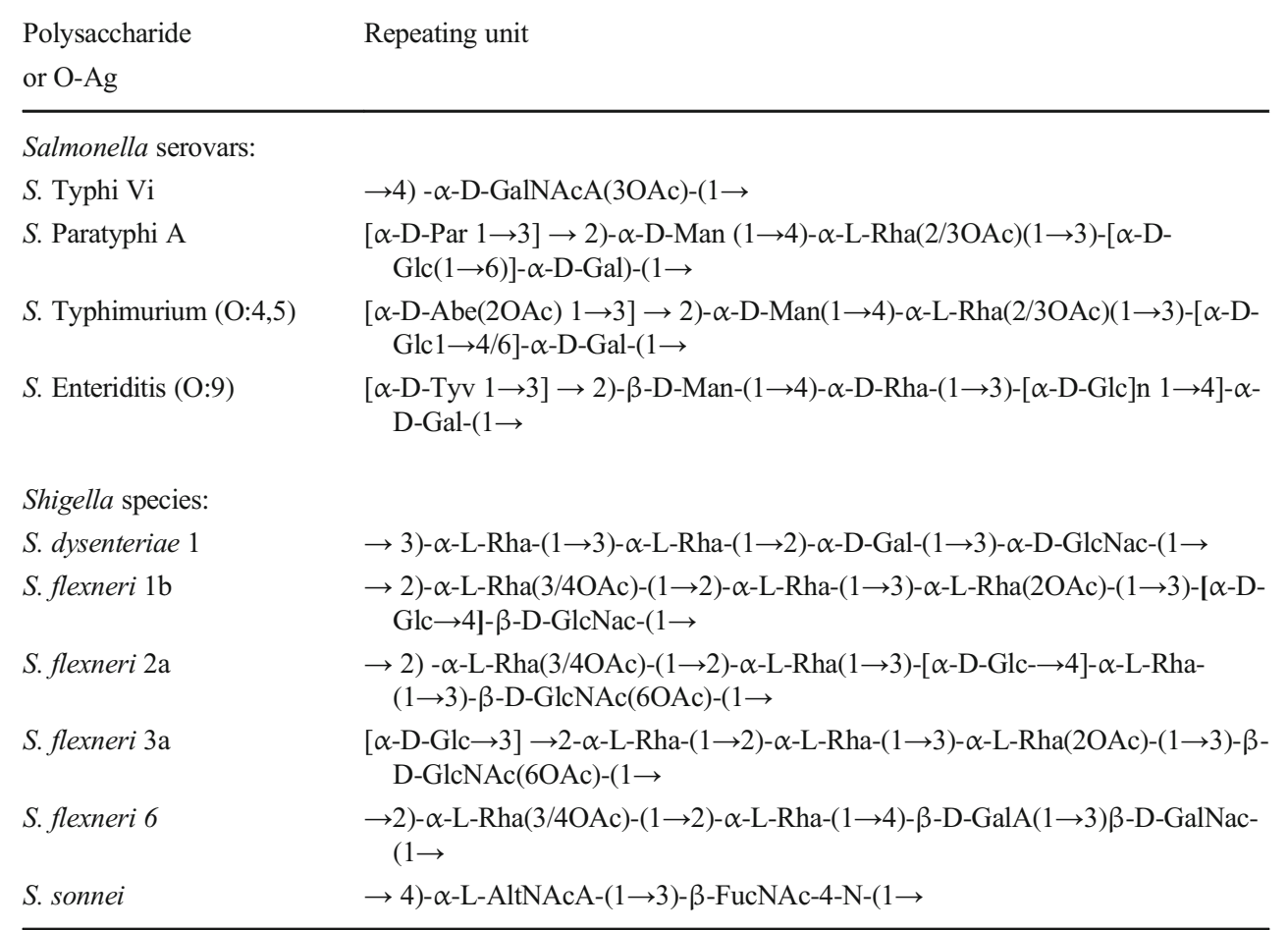

Square brackets denote branched residues. Structures adapted from Heyns and Kiessling (1967) (Vi); Ravenscroft et al. (2015a) (Paratyphi); De Benedetto et al. (2017a) (non-typhoidal Salmonella); Liu et al. (2008); Perepelov et al. (2012) (Shigella)
Immune responses to vaccines can also be affected by complexity of assembly, linker structure and carrier attachment site number or the structure, conformation and size distribution of the conjugates (Avci et al. 2019). In constructing Vi conjugates, Arcuri et al. discovered that actual conjugation chemistry in terms of linker number conjugated to the carrier protein (in this case $\mathrm{CRM}_{197}$ ) did not impact vaccine immunogenicity as well as did not inter-relate to linker length or the saccharide loading on the carrier protein (2017). While the highest IgG response post-primary dose was achieved with a full-length Vi PS-conjugate versus fragmented, the requirements for an optimal boost varied. For a full-sized antigen, the response was similar irrespective of protein conjugate, but in formulation with fragmented $\mathrm{Vi}$, after second immunisation a booster response was only observed with TT but not with $\mathrm{CRM}_{197}$ and DT that may be linked to the larger size of TT as well as its T-cell epitopes (Arcuri et al. 2017; Wessels et al. 1998; Lockyer et al. 2020). With a $\mathrm{CRM}_{197}$ conjugate, Vi PS of less than $50 \mathrm{kDa}$ gave a booster dose, while full-length $\mathrm{Vi}$ PS led to hypo-responsiveness (Micoli et al. 2020a, b). Although Vi-CRM 197 and Vi-rEPA behaved differently when tested in infants, the source and size of Vi PS were different, and these factors should also be considered (Thiem et al. 2011; Bhutta et al. 2014; Micoli et al. 2020a, b). Another study has also confirmed that immune response to Vi-DT in mice was stronger with an increasing amount of cross-linking and the subsequent size of the conjugate (An et al. 2011). Recently,
Sun et al. showed that while conjugation chemistry was not critical for immune response activation, polysaccharide stability and structure dictate the unique antigen presentation method to the T-helper cells, elucidating adaptive immune response (Sun et al. 2018). Moreover, for Vi-CRM 197 , studies in mice indicated that shorter polysaccharide have less risk of inducing unfavourable $\mathrm{T}$-independent immune response and hypo-responsiveness compared to long-chain Vi conjugates. Therefore, the elimination of T-independent responses elucidated by potential glycan candidates may be the next important control used for rational vaccine design and testing (Micoli et al. 2020a, b). For Shigella, use of a succinylated carrier protein was found to produce more immunogenic glycoconjugates compared to the unaltered version so chemical modifications of carrier proteins are also important to consider and need to be analysed (Barel and Mulard 2019). These findings highlight that in the development of novel Vi PS vaccines, the PS chain length and the carrier protein of candidate vaccines may need careful monitoring to determine their optimal immunogenicity.

\section{International guidelines of vaccine development and control: overview}

In 2014, WHO developed Guidelines for the evaluation and lot release of typhoid glycoconjugate vaccines, and these were replaced in 2020 by more comprehensive WHO 
recommendations (WHO 2014a, b, 2020b). Physicochemical tests can ensure batch consistency of conjugate vaccines and were exemplified by the WHO and Pharmacopoeia guidelines based on predecessor conjugate and unconjugated polysaccharide vaccines. Molecular size distribution, the saccharide and protein quantity and their ratios must be considered when determining the structure of the conjugate with appropriate analytical methods. The key testing areas required for vaccine quality control are described below, including the techniques used to measure the relevant structures (Table 7).

\section{Identity and compositional analysis of polysaccharide-based vaccines}

The identity of a glycoconjugate vaccine for enteric pathogens can be defined in monosaccharide composition, $O$-acetyl group quantitation and purity of the sample. ${ }^{1} \mathrm{H}$-nuclear magnetic resonance is validated as a sole routine release method for PS identity and purity, which is recommended by the United States Pharmacopeia (USP) and WHO for $S$. Typhi Vi PS and is a superior technology to less precise colorimetric techniques (although it cannot measure residual nucleic acid or protein) (Lemercinier et al. 2000; WHO 2017b; United States Pharmacopeial Convention 2018). NMR provides data on the PS structure, stability and degradation pathways, and can be used with a quantitative standard as a qNMR method to get relative molecular mass and content (WHO 2017a). Unidimensional and two-dimensional NMR spectroscopy can be used for S. Typhi and Shigella O-Ag in either glycoconjugate or GMMA preparations, and is a relatively rapid and information-rich characterisation method (Berti and Ravenscroft 2015; Raso et al. 2020). NMR spectroscopy has also proven valuable for the detection, identification and quantification of process impurities in the polysaccharides (Xu et al. 2005; Beri et al. 2019). Nevertheless, spectra are less resolved for the hydrophobic and rigid structure of tightly packed substituents in the sugar ring of Vi due to the rapid spin-spin relaxation rates, which is not ideal for differentially $O$-acetylated serotypes (Lemercinier et al. 2000).

Other methods for Vi polysaccharide quantitation include an acridine orange dye colorimetric method (Stone and Szu 1988), rate nephelometry and rocket immunoelectrophoresis (WHO 2017b). High-performance anion-exchange chromatography-pulsed amperometric detection (HPAECPAD) is a common technique applied to quantitate Vi saccharide content in drug substance and drug product using an alkaline hydrolysis method (Micoli et al. 2011). Measuring the Vi content of conjugated or non-conjugated polysaccharide vaccines by six laboratories with HPAEC-PAD resulted in good inter-laboratory comparability and produced improved results distribution of Vi content when the homologous Vi PS standard was used to quantitate the Vi content in a vaccine from the same source (Citrobacter freundii or $S$. Typhi). The rocket immuno-electrophoresis was performed by four laboratories but could have limitations when used for bulk conjugates, due to the standard-sample molecular mass disagreement. It, however, gave good results for the PS alone (WHO 2017b; Gao et al. 2019).

LPS and glycan composition in Shigella can be determined with the methods described above as well. The ${ }^{1} \mathrm{H}$ diffusionordered spectroscopy (DOSY) NMR coupled with HPLCSEC (size exclusion chromatography) with differential refractive index (dRI) can be used to detect LPS chain length, size and structure variations in S. flexneri GMMAs. The number of LPS core reducing end KDOs (2-keto-3-deoxy-octonate) is isolated and quantified by HPLC-SEC as well. The percentage of O-Ag can be determined as the molar ratio of their KDO to total KDO. O-Ag sugar content is also possible to quantify using the Dische colorimetric method (methyl pentoses (6deoxyhexoses)) (Dische and Shettles 1948). Colorimetry is less precise so physical or immuno-detection methods may be prioritised. Total $O$-acetyl content, as well as $O$-acetyl content variations, can be confirmed with 2D NMR (Raso et al. 2020). NMR and HPLC-SEC are often applied to check glycoconjugate purity as well (Berti and Ravenscroft 2015; Ravenscroft et al. 2015b). HPAEC-PAD run with appropriate standard or standard mixtures can be applied for GMMA or complex O-Ag saccharide chains to calculate the relative molar concentration of glucans (Gerke et al. 2015).

The number of polysaccharide chains bound to the carrier protein can be deduced with limited information if chain lengths are known; however, these methods do not give information on their position. The conjugation positions can be identified by mass spectrometry, but it is still a challenge to map conjugation sites in populations of polydisperse molecules. Some reports on capsular polysaccharides (CPS) show that solid-state NMR spectroscopy is a working alternative to determine PS/protein conjugation pattern and the degree of conjugation; however, it has not yet been reported for Salmonella Typhi, iNTS or Shigella conjugated vaccines (Giuntini et al. 2017). To determine sugar:protein ratio, colorimetric tests are still popular due to their low cost and relative simplicity, for example anthrone and a colorimetric protein concentration assay (Leyva et al. 2008; Ravenscroft et al. 2015b).

Standardised ELISA methods are available for immunogenicity determination. Currently, two methods have been accredited as repeatable and reliable for serological ELISAs of serum responses against Vi-based conjugates from clinical studies: commercial VaccZyme and in-house Vi-poly-L-lysine (PLL)-based immunoassays, where Vi is pre-coated with PLL to give superior results to native coating, as PS is negatively charged allowing PLL to adhere and improve Vi interaction with solid phase (Rijpkema et al. 2018; Rigsby et al. 2020). The biotinylated Vi ELISA can be used for control comparison of potencies but not for the geometric mean potencies, or 


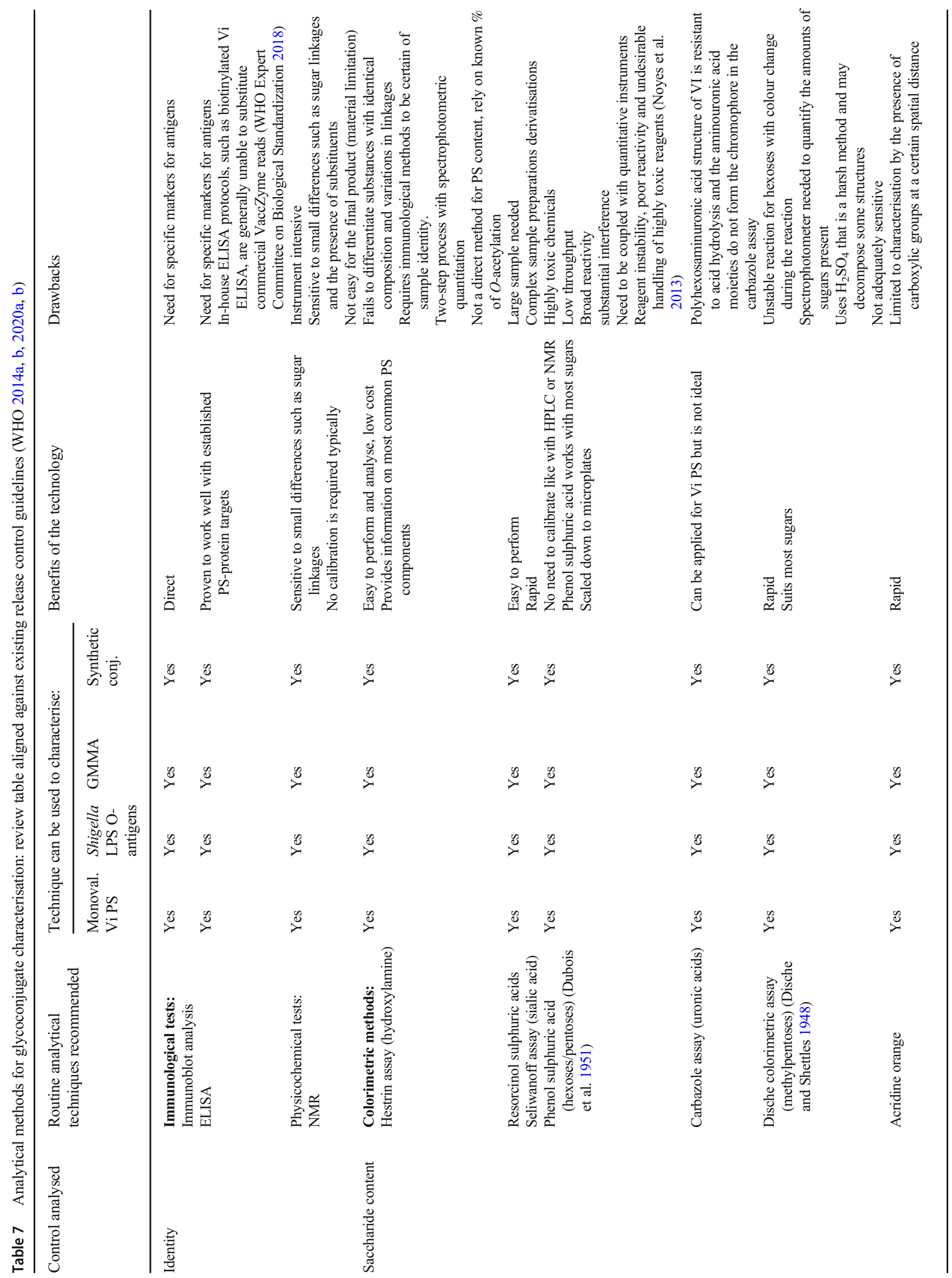




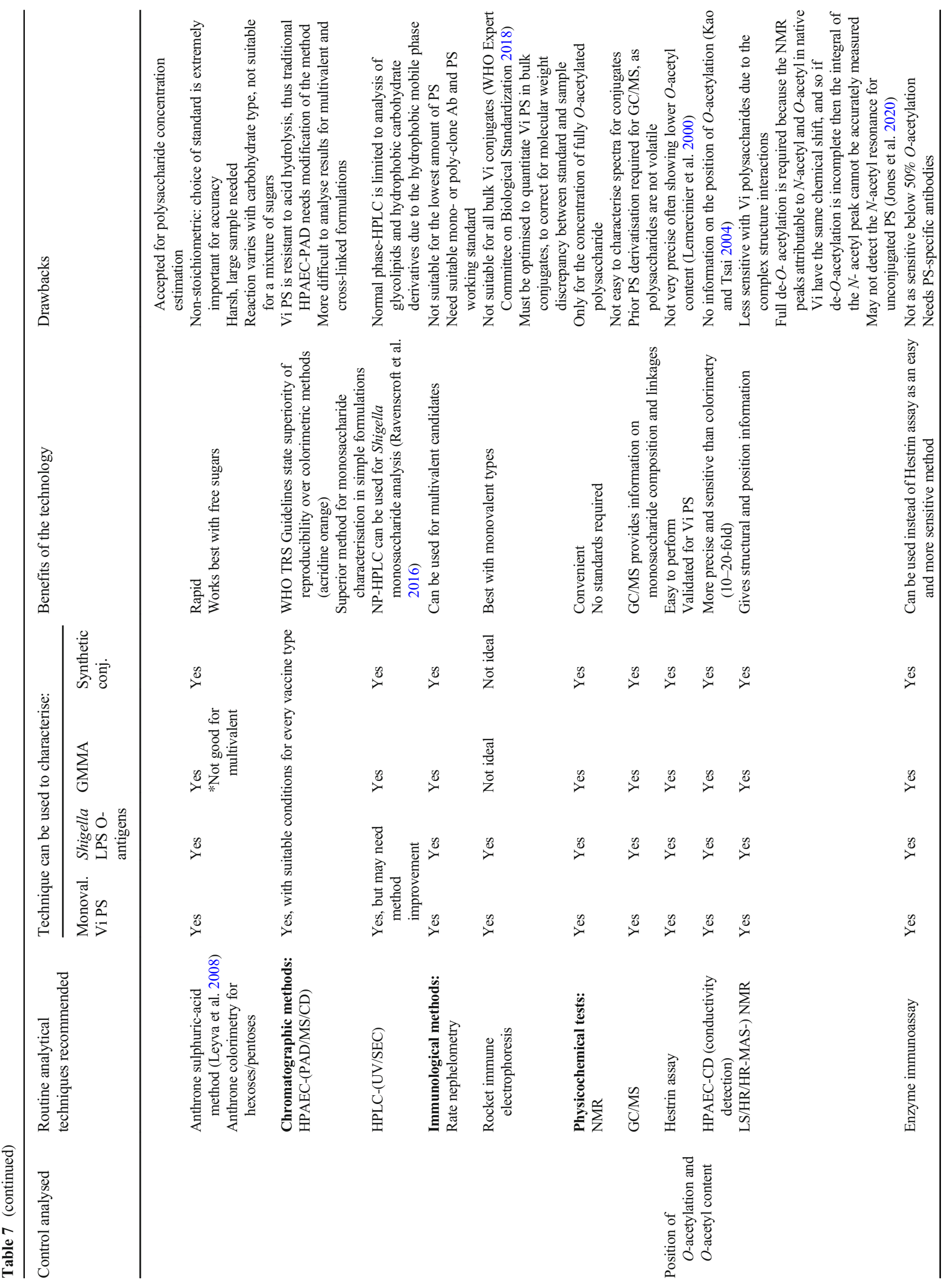




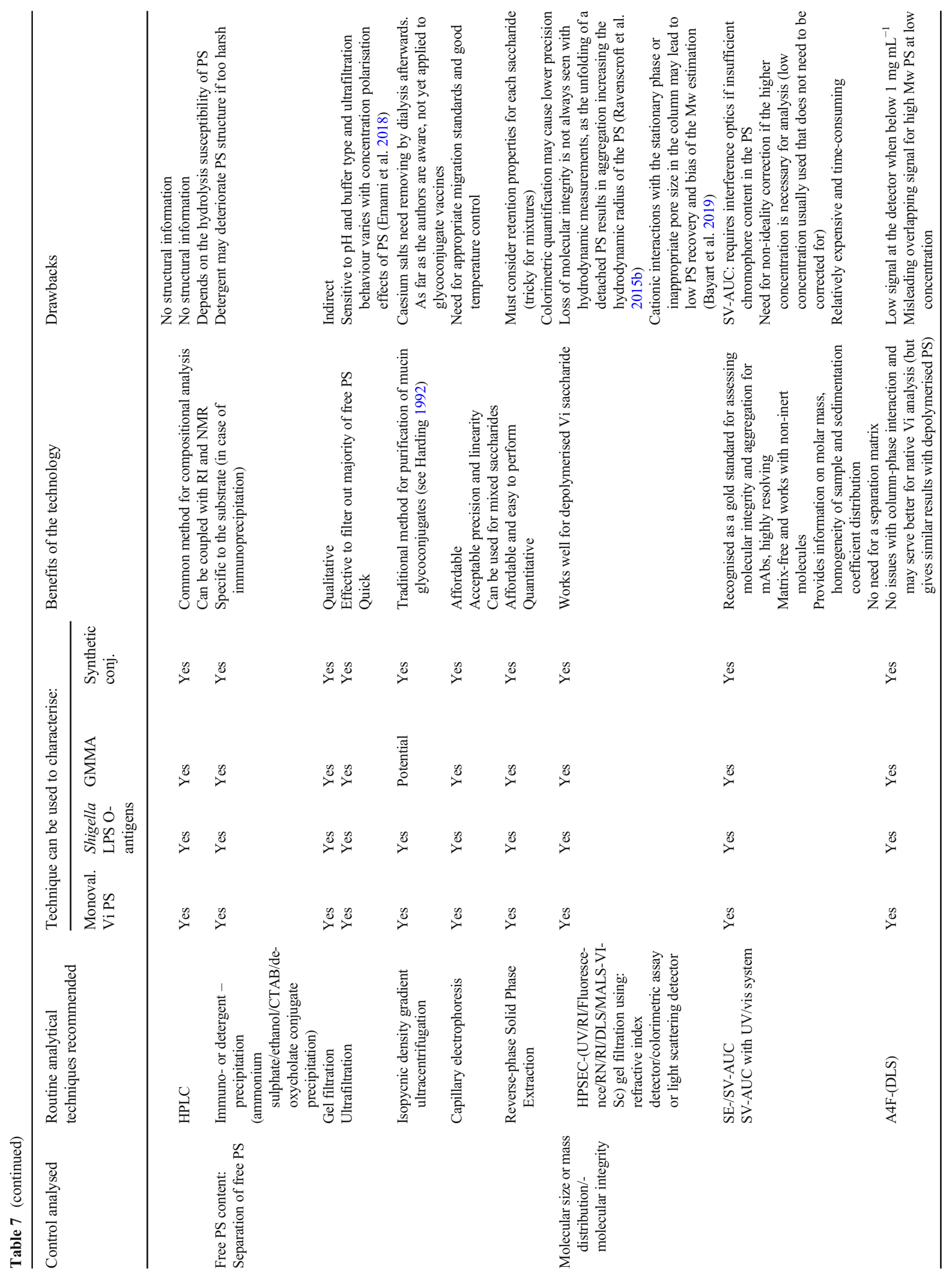




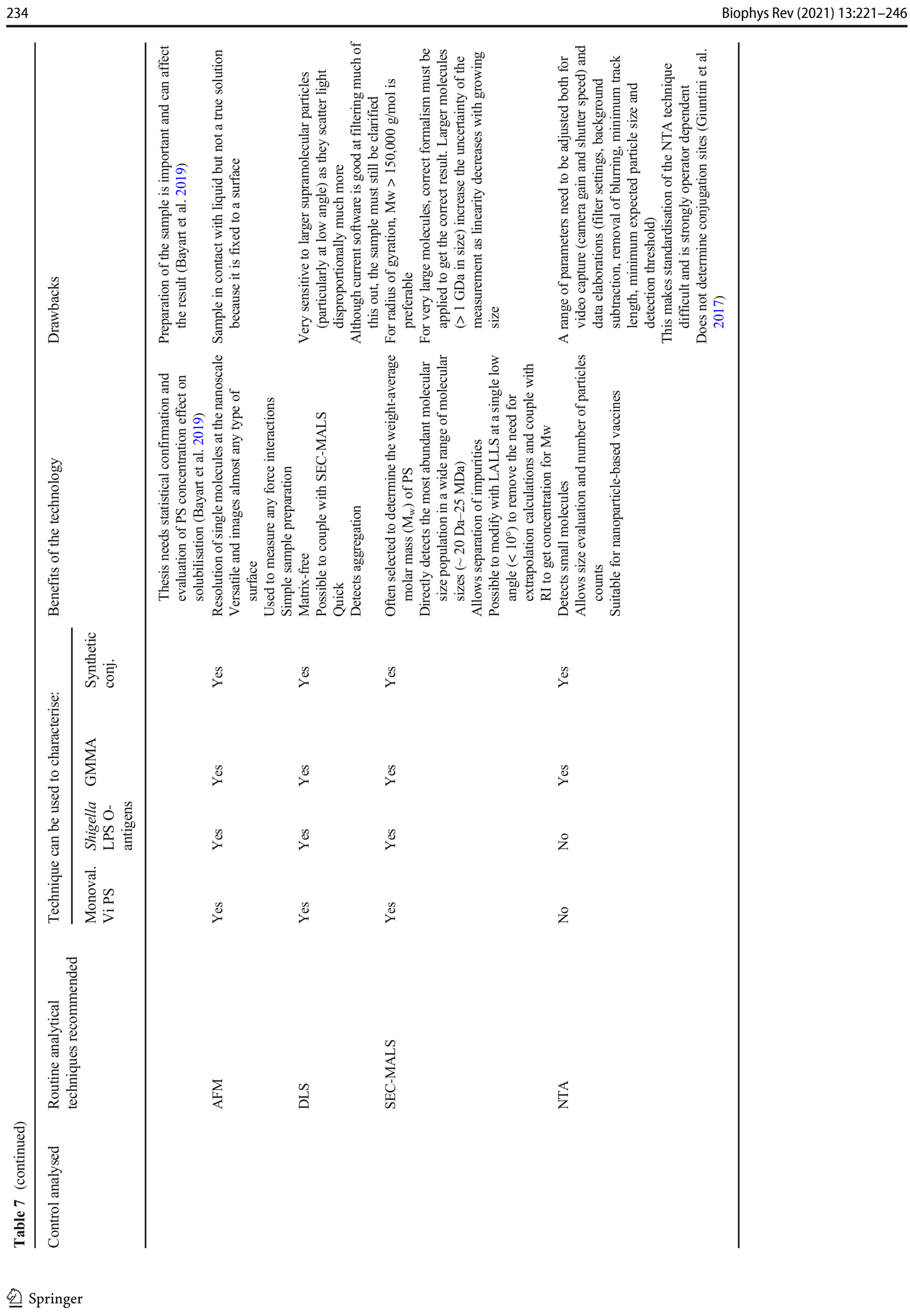


potency estimates, as it gives alternative reads to the VaccZyme ELISA (Rijpkema et al. 2018). Following the request of the WHO Expert Committee on Biological Standardization (ECBS), Vi-PLL ELISA has been finally assessed in 2020 as a suitable substitute to the VaccZyme ELISA, allowing to use this uniform non-commercial, and thus more available, method to use at a lower cost. The ViPLL procedure is publicly available and uses standard biological agents, as opposed to VaccZyme (WHO 2018; Rigsby et al. 2020). Key considerations for implementation and smooth performance are the level of reagent standardisation (reference standard), validity criteria (system and sample suitability) and the inclusion of assay-specific run controls which may be study samples representative of Vi PS vaccines (Rigsby et al. 2020).

\section{Determining 0 -acetyl content}

The most basic, cheap and straightforward method for $O$ acetyl content estimation is the colorimetric Hestrin assay (Hestrin 1949) which is routinely used with purified glycoconjugate vaccines or polysaccharide components but gives less precise information (Gao et al. 2019). Another potential approach to determine the degree of $O$ acetylation could be an enzyme immunoassay using an $O$ acetyl-specific monoclonal antibody. However, due to the importance of the $O$-acetyl pattern for vaccine immunogenicity, complementary methods to colorimetry and immunoassays were developed, enabling acetyl group detection, content and positioning on the purified CPSs. These are currently NMR, and HPAEC with conductivity detection (HPAEC-CD), although this is not yet widely used (Lemercinier et al. 2000; Kao and Tsai 2004; Hitri et al. 2019). NMR is considered to give more information on $O$ acetyl position in general and has benefits over wet chemical methods since it can be used for CPS fingerprinting and gives a wider spectrum of information; however, it becomes difficult to interpret when more complex crosslinked conjugates are evaluated. Nevertheless, ${ }^{1} \mathrm{H}$ and ${ }^{13} \mathrm{C}$ NMR coupled with mass spectrometry was applied successfully to detect $O$ - and $N$-linkages in $\mathrm{Vi}$ PS in a GMMA construct (2020). HPAEC-CD is up to 20 times more sensitive compared with the Hestrin test, requires a smaller amount of material compared to NMR and is a superior method to evaluate monosaccharide composition (Mulard 2017).

While circular dichroism (CD) is commonly applied for the characterisation of carrier protein integrity, effect of conjugation and stability determination, a recent study has shown its potential for monitoring $O$-acetylation (Jones et al. 2020). A strong signal from the Vi, unusual to polysaccharides, is observed in the far-UV from $O$-acetylated and non- $O$-acetylated residues in the $\mathrm{Vi}$. With a larger amount of information generated by CD for Vi compared to other conjugates, it may become a useful method to monitor vaccine stability by analysing the degradation or de- $O$-acetylation behaviour of the polysaccharide. This method poses larger uncertainty when reading weak spectra. To assess the suitability of CD for this application, more detailed data comparisons from orthogonal methods and corrections for specific saccharides are required (Jones et al. 2020).

\section{Detection of polysaccharide degradation or detachment in vaccine products}

Free, unconjugated PS content is the main indicator of vaccine stability and inversely correlates with its potency, or effective dose; a product with increased free saccharide content could be less immunogenic, due to a lower amount of conjugated saccharide, and the potential for unconjugated saccharide to neutralise pre-existing antibody. It can be quantified successfully by only a limited number of methods that allow reproducibility. This measurement is reflecting the stability of the glycoconjugates. To determine free PS content, two steps are required: free PS separation and its quantification. The first step can routinely be done by chromatography (size, ion-exchange, hydrophobic interaction), chemical precipitation with acid or detergents, ammonium sulphate or ammonium adsorption, capillary electrophoresis, gel filtration, centrifugal ultrafiltration, ultracentrifugation, solid-phase extraction or immunoprecipitation. The second step can be performed using colorimetry or immunoblotting or by using physicochemical techniques (HPLC, HPAEC-PAD or gas chromatography (GC) post-hydrolysis), which are more robust approaches (Ravenscroft et al. 2015b).

Giannelli et al. found that UV-coupled HPLC-SEC detection of free Vi PS proved to be problematic due to the variable extinction coefficient of $\mathrm{Vi}$ that depends on $\mathrm{O}$-acetyl content and chemical modifications required for carrier attachment (2017). An alternative free PS purification method was introduced using the Capto Adhere resin separation that worked irrespective of conjugated protein and delivered a more sensitive and quantitative measurement for a range of $\mathrm{Vi}$ lengths. It works by entrapment of intact conjugates and HPAEC-PAD quantification of the $\mathrm{Vi}$ component recovered in the filtrate. Capto Adhere resin separation coupled with HPAEC-PAD achieved $75-120 \%$ recovery of free Vi PS. The absence of conjugates in the buffer strip solutions was verified by a dotblot assay and HPLC-SEC chromatograms (Giannelli et al. 2017). Their most recent paper on Vi detection suggests an optimised hydrolysis conditions for the HPAEC-PAD detection method to get more accurate data on the de- $O$ - and de- $N$ acetylated Vi PS monomer, discussed later in the review. A deoxycholate (DOC) precipitation method (Lei et al. 2000), in 
which free saccharide is recovered in the supernatant of DOCprecipitated protein samples, has also been shown to measure reproducible \% free saccharide levels (Fig. 1).

Another one-step immunoprecipitation method based on anti-carrier protein antibody-coupled Sepharose beads was developed at the Serum Institute of India. The method claims to overcome HP-SEC limitations and can be applied for free PS from multivalent polysaccharide-protein conjugate vaccine formulations, total PS content and percent adsorption of polysaccharides (Serum Institute of India 2013).

\section{Molecular size profiling and solution properties of glycoconjugate vaccines}

Glycoconjugates manufactured by conjugating PS to a carrier protein will have increased mass, altered shape and possibly changes in behaviour in solution compared to their individual components. Flexible interactions in solution and intermolecular interactions can be influenced by the character of the polysaccharide as well as the protein, and changes to protein sites required for antigen processing and T-cell epitope accessibilities could be affected. The type of carrier protein that is conjugated may influence the choice of analytical techniques. While monovalent "sun type", for example $\mathrm{CRM}_{197}$ conjugates may be more straightforward to characterise, TTbased cross-conjugated glyco-vaccines (e.g. "lattice type") may be more challenging (Barel and Mulard 2019). Proven methods to measure molecular size distribution, hydrodynamic size, viscosity and solution behaviour (of the glycoconjugate or the separate polysaccharides and/or carrier proteins) include SEC-MALS/UV/RI/Viscosity, degree of polymerisation (repeating unit analysis), analytical ultracentrifugation and optical spectroscopy (MacCalman et al. 2019).

When determining molecular integrity of polysaccharides in solution, challenges linked to the polydisperse nature of the saccharides arise, in addition to their higher non-ideality (through co-exclusion and polyelectrolyte effects) compared to proteins. SEC-MALS is considered a useful technique with minimal non-ideality effect due to the dilution from the columns. However, it relies on interaction with a matrix, is dependent on $\%$ recovery and sometimes ignores hydrodynamic changes brought about by the PS moiety detachment or protein unfolding which increases the apparent relative size, as if the conjugate structures were intact (Ravenscroft et al. 2015b). In addition, the separation columns have a size separation limit, and the assumption must be made; there are no anomalous interactions with the polymer matrix which makes up the separation columns. SEC-MALS/RI/viscosity of Vi polysaccharides in different eluents demonstrated the need to consider column choice and buffers salts to obtain representative recoveries and highlighted the differences that salt composition makes to hydrodynamic size and viscosity (Hitri et al. 2019). See also the following examples of other vaccine-relevant oligo- and poly-saccharide components (Jumel et al. 2002; Bardotti et al. 2008; Harding et al. 2012; Lockyer et al. 2015).

Analytical ultracentrifugation (AUC) - a matrix-free method - has also been extensively applied for molecular distribution and molecular weight of polysaccharides (see, for example Harding et al. 2010 and 2015 \& references cited therein). The two main types of AUC are sedimentation velocity and sedimentation equilibrium. Sedimentation velocity provides separation based on size and shape, and analysis, normally from Rayleigh interference optical records. Sedimentation coefficient distributions provide a measure of heterogeneity, and if conformational information is known, the distributions can be converted into molecular weight distributions using the "Extended Fujita" method. Sedimentation equilibrium - at slower speeds than for sedimentation velocity - gives optical records that are directly related to molecular weight. Some caution is necessary with regard to nonideality, either by working at low concentration to minimise these effects (the lowest working concentrations are $\sim 0.05$ $\mathrm{mg} / \mathrm{mL}$ for sedimentation velocity and $\sim 0.4 \mathrm{mg} / \mathrm{mL}$ for sedimentation equilibrium) or by making measurements at different concentrations and performing an appropriate extrapolation to zero concentration where non-ideality effects vanish. Conformation and flexibility can be estimated using powerlaw coefficients (relation between sedimentation coefficient and molecular weight) and the Wales-van Holde ratio (ratio of the "non-ideality" concentration dependence sedimentation coefficient parameter to the intrinsic viscosity) and using the persistence length calculations based on "HYDFIT" combinations of SEC-MALS, viscosity and AUC data (see Abdelhameed et al. 2012, 2016a, b) for examples with Hib and meningococcal-TT conjugates.

Optimal spectroscopic methods such as near-UV CD and Trp fluorescence spectroscopy also can report on the mobility and solvent accessibility of aromatic amino acid side chains. The effects of conjugation on these groups, as well as the secondary structure and folding of a carrier protein, as determined by far-UV CD, are important characterisation methods and will remain important for the initial characterisation of novel recombinant carrier proteins. Carrier protein and conjugate molecule characterisation and assessment of thermal stability have been described for these carrier proteins: $\mathrm{CRM}_{197}$ (Crane and Bolgiano 1997; Bolgiano et al. 2001; Ho et al. 2001; Bardotti et al. 2008), TT (Ho et al. 2002; Lockyer et al. 2015), rEPA (Ho et al. 2006), DT and protein D (Lockyer et al. 2015). Structural effects on conjugated carrier proteins have been demonstrated to correlate with reduction in the immune response against the carrier (Beresford et al. 2017).

\section{Novel Shigella vaccines: glycoconjugates and GMMA}

Several vaccines in clinical trials are currently targeting the most common serotypes of Shigella (Table 5); however, a 
more promising direction to take maybe towards multiprotection formulations (WHO 2020a). The WHO suggested existing recommendations for glycoconjugate vaccines control to be followed in product guidance for Shigella vaccines (WHO 2020a). Since Shigella vaccines are based on the O-polysaccharides anchored to the LPS, they are more challenging to produce and control. Conjugation chemistry of multiple antigens is structurally complex, and LPS requires laborious extraction and detoxification, which may affect molecular integrity. LPS and lipoproteins in GMMA act as immunostimulatory components, which alter their reactogenicity: the level of LPS acylation is important for determining the potency and safety of vaccines (De Benedetto et al. 2017a).

Alternatives to multistep chemical conjugation include bioconjugation using transformed $E$. coli, GMMA vesicles and synthetic conjugates (Kis et al. 2018). GMMA vaccines are already manufactured in GMP-quality conditions against S. sonnei, S. flexneri and nontyphoidal Salmonella strains (Gerke et al. 2015). Novel GMMA formulations are usually characterised by conventional analytical methods used for other glycoconjugates, being verified for their use (Micoli et al. 2020a, b; Raso et al. 2020). For GMMA, O-Ag core sugar content can be quantified by HPAEC-PAD, after performing acid hydrolysis directly on GMMA. After O-Ag extraction, total sugar content can be done using a suitable colorimetric method, or NMR, which also provides structural information and assesses purity (Raso et al. 2020). The concentration of O-Ag can be determined with a combination of NMR and HPAEC-PAD (Gerke et al. 2015). Protein and lipid content will need to be determined to calculate LPS/protein ratios.

The GMMA size distribution can be determined by dynamic light scattering (DLS). Other methods described for GMMA particle size include multiangle light scattering (MALS) that can be coupled to the high-performance liquid chromatography-size exclusion chromatography (HPLCSEC/MALS, which also helps to check sample purity) and nanoparticle tracking analysis (NTA) (De Benedetto et al. 2017b).

Meloni et al. used hydrolysed GMMA (1\% acetic acid v/v, neutralised with $28 \% \mathrm{NH}_{4} \mathrm{OH}$ ) from Salmonella Typhimurium SL1344 $\Delta$ tolR O-antigen (O-Ag) PS purified by a tangential flow filtration method to separate and analyse $\mathrm{O}-\mathrm{Ag}$, and it was revealed that such method strips off the low molecular mass O-Ag completely in GMMA and wild-type bacteria, shown by HPLC analysis of the batches (2015). Saccharide content was then analysed by HPAEC-PAD, confirming the differential monosaccharide ratios of low and medium molecular mass antigens in GMMA and wild-type bacteria. This O-Ag has more similarity to an LPS, which may be relevant for Shigella GMMA characterisation. This method highlights that $\mathrm{O}-\mathrm{Ag}$ purification must be optimal to fully characterise GMMA constituents; however, the approach may be useful to evaluate the proportion of larger Mw components with HPAEC-PAD, and seems to work well as a direct O-Ag separation method in enteric Salmonella (Micoli et al. 2013).

Ravenscroft et al. described analytical techniques used to prove the structural integrity of $S$. dysenteriae type 1-EPA glycoconjugate produced by innovative biosynthetic Escherichia coli glycosylation that are suitable for characterisation of other Shigella serotypes and based on conventional approaches like (RP/NP)HPLC-SEC/UV, immunoblot detection, $1 \mathrm{D}$ and 2D NMR and MALDI MS/MS posttrifluoroacetic acid (TFA) hydrazinolysis (2016). The recovery of the Rha repeating unit was low as the free 6-deoxy hexose decomposed due to hydrolysis employed to release GlcNAc, suggesting the importance of optimal hydrolysis conditions. The $S$. dysenteriae type 1 O-PS structure was fully characterised by 1D and 2D NMR spectroscopy with full information provided on the Gal, two Rha and GlcNacspin systems evaluated by the use of $1 \mathrm{D}$ TOCSY, $2 \mathrm{D}{ }^{1} \mathrm{H}-{ }^{1} \mathrm{H}$ (COSY and TOCSY) and ${ }^{1} \mathrm{H}-{ }^{13} \mathrm{C}$ (HSQC, HMBC and HSQCTOCSY) experiments (Ravenscroft et al. 2016).

\section{Part III}

\section{Emerging techniques to aid glycoconjugate design}

\section{Structural vaccinology}

Structurally complex polysaccharides conjugated to carrier proteins may pose a risk of exerting immunodominance over a less immunogenic but essential epitopes in a combination vaccine, which is highly undesirable for immunisation. Neoepitopes that form due to degradation or modification of polysaccharides may adversely impact the immunogenicity of native polysaccharides. Getting access to comprehensive structural evaluation of the mechanisms of binding and epitope characterisation tools may help to expand current understanding of how immunodominance is dictated in glycoconjugates and even provide novel data allowing for the enhancement of the antigen structure to achieve adequate and balanced protection (Anish et al. 2014).

\section{Computational methods to facilitate synthetic antigen design}

Establishing and evaluating carbohydrate structure-function relationships that affect immunogenicity are topics of high interest. Glycan shape complexity, chain flexibility, dynamic properties of pyranose rings and diversity of functional groups make structural analysis a priority that would benefit from multiple approaches. Where 3D physicochemical methods are not informative enough, computational methods may 
supplement the characterisation of structural determinants of affinity, specificity and antigenicity. In silico simulations could allow for a study of conjugation and binding at an atomic level when they cannot be experimentally deduced. Computational methods allow for tracking molecular effects on saccharide antigenicity (through enthalpy and entropy changes), which is important for the selection of the right candidate for synthesis. Moreover, currently used methods, such as X-ray diffraction or NMR spectroscopy, may provide biased results for large saccharides in more dilute solutions. While NMR techniques are relevant for homogeneous saccharide characterisation, implications linked to molecular mass limit the scope of applications for large antibody-PS complexes and often need coupling with in silico molecular dynamics (MD) simulations for structural definition (Anish et al. 2014). MD simulations of vaccine-relevant PS that consider chain length and counterions in a hydrated environment have identified potential epitopes and conformer distributions for Vi PS and O-Ag (Hitri et al. 2019; Hlozek et al. 2020).

Characterisation and structural information for glycoconjugates cannot be achieved by a single method; thus, multiple biophysical techniques combined with computational methods allow deduction of carbohydrate structure-function analysis and antibody interaction (Anish et al. 2014). Molecular modelling coupled with NMR spectra of the molecular structure has been implemented for more optimal design and immunogenicity of Shigella SD1 synthetic glycoconjugates. It allowed identification of a preferred hairpin conformation of a synthetic O-Ag (the ABCD tetrasaccharide) that was representing the native $\mathrm{O}-\mathrm{Ag}$ more closely. A hairpin conformation for ABCDA' saccharide and larger O-Ag parts in a helix conformation allowed partial exposure of $\mathrm{B}$ and $\mathrm{D}$ monosaccharides, thereby inducing antibody recognition that could lead to an enhanced anti-O-Ag antibody response, which is a key parameter for vaccine potency and safety considerations (Barel and Mulard 2019). These methods provide alternatives to the 3D structural analysis of polysaccharides by small-angle X-ray/neutron scattering, X-ray crystallography and NMR (Anish et al. 2014).

\section{Current efforts for better polysaccharide characterisation}

\section{Modified methodologies of HPAEC-PAD for more precise $\mathrm{Vi}$ saccharide quantitation}

HPAEC-PAD is currently the most robust and detailed quantification technique used for PS compositional analysis of bacterial vaccines (Rohrer 2020). However, due to the low susceptibility of Vi and other uronic acids to PS depolymerisation, this method is constantly being optimised for more accurate and precise readings. While strong alkaline-based depolymerisation is efficient for $\mathrm{Vi}$ in monovalent formulations, combinations with $S$. sonnei O-antigen, where co-elution with Vi may occur, are likely coming from the degradation of the alturonic acid (Gerke et al. 2015; Giannelli et al. 2020). Giannelli et al. further improved the hydrolysis step for HPAEC-PAD by suggesting acid hydrolysis with simultaneous use of trifluoroacetic and hydrochloric acid (TFA: $\mathrm{HCl}$ in a 2:13 v/v ratio), to prevent such co-elution and verified product formation using ${ }^{1} \mathrm{H}$ NMR, ${ }^{13} \mathrm{C}$ NMR, COSY and HSQC (Giannelli et al. 2020). The presence of 2-amino-galacturonic acid monosaccharide in equilibrium between $\alpha$ and $\beta$ conformations was also observed for $\mathrm{Vi}$. Recovery of $101 \%$ was reported of reduced (de- $O$ - and de- $N$ acetylated) monosaccharides with increased sensitivity due to the high yield of hydrolysis product(s) compared to the depolymerisation method. This procedure could facilitate the development of standards in enteric vaccines containing both Vi PS and O-Antigens that also contain amino uronic acids (Giannelli et al. 2020).

We have compared the novel HCl:TFA hydrolysis method for Vi PS quantitation of a typhoid conjugate vaccine containing $S$. Typhi Vi PS, with the standard $\mathrm{NaOH}$ hydrolysis conditions (Gao et al. 2019) using WHO International Standards for the polysaccharides (Fig. 1).

The content of $\mathrm{Vi}$ saccharide in a typhoid conjugate vaccine was quantified using WHO International Standards for Vi PS (Gao et al. 2019). Standards and vaccine samples were base depolymerized with $2 \mathrm{M}$ sodium hydroxide for $4 \mathrm{~h}$ at $110{ }^{\circ} \mathrm{C}$ (panels a to c) or acid-hydrolysed with $10 \%$ TFA- $8 \mathrm{M}$ $\mathrm{HCl}$ for $4.5 \mathrm{~h}$ at $80^{\circ} \mathrm{C}$ (panel d), following the recovery of unconjugated PS in the supernatant of a vaccine sample precipitated by sodium deoxycholate $(1 \% \mathrm{w} / \mathrm{v}) \mathrm{pH} 8.0$ and $\mathrm{HCl}$ (0.04 M) (Lei et al. 2000). The separation was performed on a CarboPac PA-1 column $(2 \mathrm{~mm})$ at $25^{\circ} \mathrm{C}$ with an Amino Trap as a guard column. Base-treated samples were eluted at a flow rate of $0.25 \mathrm{~mL} / \mathrm{min}$ for $30 \mathrm{~min}$, and with elution conditions of 0-2 min, $100 \mathrm{mM} \mathrm{NaOH}, 40 \mathrm{mM} \mathrm{NaNO}_{3} ; 2-22,100 \mathrm{mM}$ $\mathrm{NaOH}, 40-150 \mathrm{mM} \mathrm{NaNO}_{3}$ (Gao et al. 2019); acidhydrolysed Vi was run at $0.375 \mathrm{~mL} / \mathrm{min}$ using isocratic elution with $400 \mathrm{mM} \mathrm{NaOH}$ for $15 \mathrm{~min}$. $N$-Acetyl glucosamine-6phosphate $(10 \mu \mathrm{g} / \mathrm{mL})$ (peak 1) was injected in samples and standards to normalise the Vi signal in base-treated samples. Standard curves were constructed using 27, 9, 3, 1 and $0.5 \mu \mathrm{g} /$ $\mathrm{mL}$ Vi PS shown in panels $a$ and $b$ as alternating solid and dotted lines (peak 2) from $C$. freundii (panel a) or $S$. Typhi (panel b) polysaccharide samples. The vaccine sample (panel c) injected was $10 \mu \mathrm{g} / \mathrm{mL}$ Vi PS to quantify free, unconjugated (dotted line) or total Vi PS (solid line). Panel D of acidhydrolysed standards and sample shows from top to bottom, $27(\mu \mathrm{g} / \mathrm{mL})$ C. freundii $\mathrm{Vi}, 27$ S. Typhi Vi, 9 C. freundii $\mathrm{Vi}, 9$ $S$. Typhi Vi and total saccharide vaccine sample. Samples were injected in duplicate. For base-treated samples, Vi eluted within the expected time interval, at about $14.3 \mathrm{~min}$, and both standards yielded $R^{2}>0.98$. For acid-hydrolysed samples, Vi eluted at about $5.4 \mathrm{~min}$ and the signal was 6 times higher. 

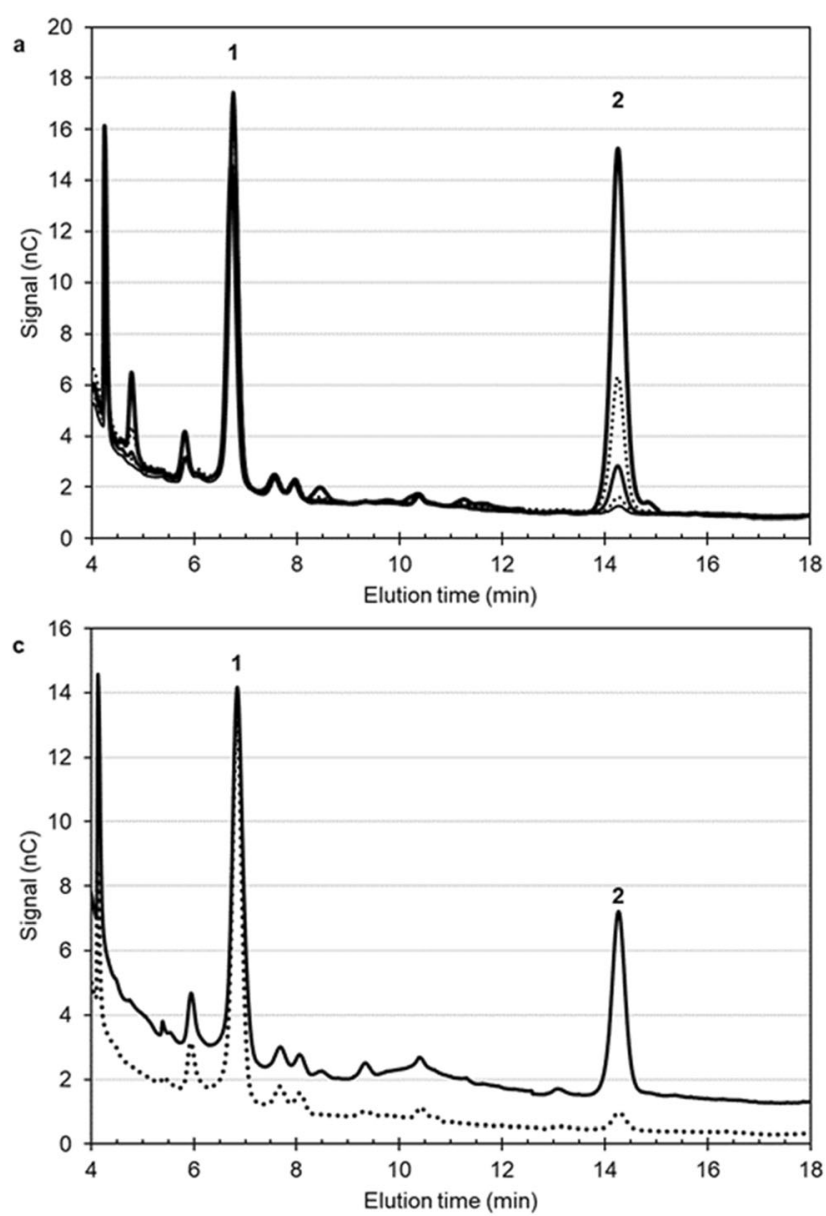
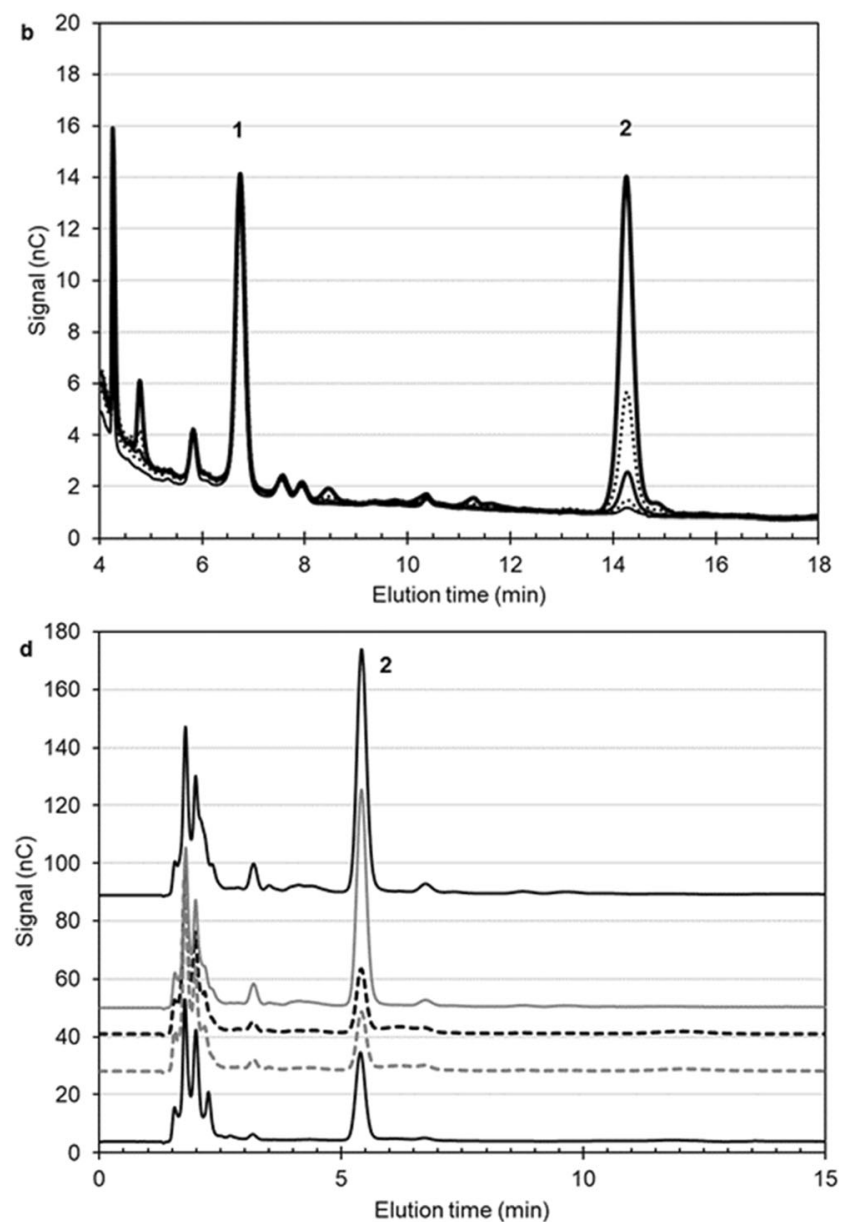

Fig. 1 HPAEC-PAD chromatograms obtained from NaOH-depolymerized (a-c) and TFA-HCl-hydrolysed (d) C. freundii Vi polysaccharide (a), S. Typhi Vi (b) polysaccharide and a typhoid conjugate vaccine (c) The individual traces are described in the text

Both the Vi PS concentration ( $\mu \mathrm{g}$ per dose) and $\%$ free Vi PS were lower using the $C$. freundii sample by $7.7 \%$ and $4.3 \%$, respectively, compared to native Vi PS standard under base treatment. This suggested that $C$. freundii is an imperfect alternative to the native $\mathrm{Vi}$ that could underestimate Vi content in the sample. Homologous source Vi PS should be used for quantitation (Gao et al. 2019). Linear standard curves were obtained (up to $10 \mathrm{ug} / \mathrm{ml} \mathrm{Vi)} \mathrm{with} \mathrm{the} \mathrm{acid} \mathrm{hydrolysis} \mathrm{method,}$ which has the potential to separate amino-uronic acids and OLPS with higher sensitivity. The establishment of an acidstable internal standard for quantitation is required.

\section{Methods for robust characterisation of multivalent combinations and Shigella antigens}

Shigella LPS and O-Ag analysis may be a laborious task due to a vast diversity of antigens in different serotypes. Currently, primary testing to identify the O-Ag usually limited to techniques using specific identifiers for the serotype detection, such as membrane insertion and ELISAs (Stromberg et al. 2017). The lack of sensitive and selective antigen ligands suitable for every serogroup remains a major problem. Ravenscroft et al. also applied capillary gel electrophoresis for Shigella dysenteriae 1-EPA bioconjugates mentioned above to get better resolution of individual repeating units, as well as to monitor their integrity (Ravenscroft et al. 2016).

\section{Combination methods suggested for future analysis and vaccine design}

Coupling high-resolution mass spectrometry and ${ }^{1} \mathrm{H}$ NMR techniques was tested with Neisseria meningitidis serogroup $\mathrm{B}$, enabling simultaneous analysis of conjugation reaction course and final products (Yu et al. 2018). However, the utilisation of mass spectrometry with polydisperse macromolecules (10-100 kDa), like $S$. Typhi O-PS, provides less information as in the case of glycoconjugates derived from synthetic antigens or less complex glycans (Méndez et al. 2018).

The NEWCARBOVAX project was launched in 2017, which showcases an effective vaccine design platform that has been tested with CPSs from $S$. Typhi, Hib and type Ib group B Streptococcus, that successfully induced T helper cells ( $\mathrm{T}$ carbs) successfully (CORDIS | European 
Commission 2020). This platform is going to be a helpful approach if coupled with research into novel conjugation chemistry approaches in this field.

Any of the new and existing conjugates under development may benefit from the application of Quality by Design principles in the development and testing of vaccines and intermediates. Current technologies discussed in this review are focused on more common glycoconjugate formulations. Nanoparticle-based vaccines, protein capsular matrix vaccines and liposomal encapsulation of polysaccharides are becoming a new trend in vaccine design and will require new validated methods of quality control.

Lastly, classical approaches to evaluating thermal unfolding and stability for lipid-based vaccines destined for hot climates may need to be reconsidered to account for their membrane dynamics. The lipid composition of the membranes may affect membrane phase transitions at relatively lower temperatures than expected for the polysaccharides and some protein domains, and the impact of such dynamics on immunogenicity, safety and protection will need to be considered as shown for Salmonella and Shigella GMMAs using differential scanning calorimetry in combination with monoclonal antibody binding and immunogenicity (Palmieri et al. 2021).

\section{Summary}

Limited antibiotic treatment options against the emerging burden of typhoid fever and shigellosis infections and the continuing need for cleaner water, hygiene and sanitation emphasise the urgent need for effective preventions against communicable enteric diseases. Glycoconjugate vaccines could become a promising solution targeting the most infectious strains of these bacteria. With the updated WHO recommendations on the quality, safety and efficacy of typhoid conjugate vaccines adopted by the ECBS in 2020 and SAGE recommendations for typhoid conjugate vaccines to be used as preventive measures in endemic countries or where there is a high burden of antimicrobial resistance (WHO 2017a), analytical methods for evaluating typhoid conjugate vaccines are becoming established. The efforts to produce protocols for Shigella and non-typhoidal Salmonella vaccine development will be supported by academia, institutions, public health bodies and funding organisations over the next few years (NIBSC 2020). These are major steps towards faster commercialisation of glycoconjugates and more complex vaccines to address an emerging global need for enteric disease prevention.

This review highlights applications of conventional methods of glycoconjugate and more complex vaccine structures. Alterations to experimental conditions are constantly made and protocols are being modified together with reference standards to serve the demand for higher accuracy for glycoconjugates that are less susceptible for hydrolysis or behave differently in solution. Together with modern computational approaches, a more precise design of glycoconjugates is possible, which allowing better predictions on vaccine behaviour, structural changes in solution and immunogenicity, which can be applied to a broad spectrum of vaccines. More validation is required to establish the most effective and suitable methods for glycoconjugate and more complex vaccine analysis to bring uniformity to existing protocols, aiding future achievements in this area of research.

Acknowledgements The authors are grateful to Dr. Gianluigi De Benedetto and Dr. Sjoerd Rijpkema for their review of the manuscript and to G.DeB. for method optimisation.

Author contributions Aleksandra Bazhenova performed the literature search and drafted the review, which was supervised by Stephen Harding, and critically revised by all of the authors. Aleksandra Bazhenova performed the HPAEC-PAD analysis, which was supervised by Fang Gao and Barbara Bolgiano.

Funding Funding to A.B. was provided by the National Centre for Macromolecular Hydrodynamics, School of Biosciences, University of Nottingham. S.E.H. was supported by the UK Biotechnology and Biological Sciences Research Council [grant number BB/T006404/1] and the Norwegian Ministry of Education and Research.

\section{Declaration}

Conflict of interest The authors declare no conflict of interest.

Open Access This article is licensed under a Creative Commons Attribution 4.0 International License, which permits use, sharing, adaptation, distribution and reproduction in any medium or format, as long as you give appropriate credit to the original author(s) and the source, provide a link to the Creative Commons licence, and indicate if changes were made. The images or other third party material in this article are included in the article's Creative Commons licence, unless indicated otherwise in a credit line to the material. If material is not included in the article's Creative Commons licence and your intended use is not permitted by statutory regulation or exceeds the permitted use, you will need to obtain permission directly from the copyright holder. To view a copy of this licence, visit http://creativecommons.org/licenses/by/4.0/.

\section{References}

Abdelhameed AS, Morris GA, Adams GG, Rowe AJ, Laloux O, Cerny L, Bonnier B, Duvivier P, Conrath K, Lenfant C, Harding SE (2012) An asymmetric and slightly dimerized structure for the tetanus toxoid protein used in glycoconjugate vaccines. Carbohydr Polym 90: 1831-1835. https://doi.org/10.1016/j.carbpol.2012.07.032

Abdelhameed AS, Adams GG, Morris GA, Almutairi FM, Duvivie P, Conrath K, Harding SE (2016a) A glycoconjugate of Haemophilus influenzae type $\mathrm{b}$ capsular polysaccharide with tetanus toxoid protein: hydrodynamic properties mainly influenced by the carbohydrate. Sci Rep 6:22208. https://doi.org/10.1038/srep22208

Abdelhameed AS, Morris GA, Almutairi F, Adams GG, Duvivier P, Conrath K, Harding SE (2016b) Solution conformation and 
flexibility of capsular polysaccharides from Neisseria meningitidis and glycoconjugates with the tetanus toxoid protein. Sci Rep 6: 35588. https://doi.org/10.1038/srep35588

Adisinsight.springer.com (2020a) Typhoid conjugate vaccine International Vaccine Institute/Incepta/SK Bioscience/PT Biofarma - Adisinsight. https://adisinsight.springer.com/drugs/800048060. Accessed 8 Aug 2020

Adisinsight.springer.com (2020b) Typhoid-tetanus toxoid conjugate vaccine - Cadila Healthcare - Adisinsight. https://adisinsight.springer. com/drugs/800047578. Accessed 8 Aug 2020

Ahsan S, Rahman S (2019) Azithromycin resistance in clinical isolates of Salmonella enterica serovars Typhi and Paratyphi in Bangladesh. Microb Drug Resist 25:8-13. https://doi.org/10.1089/mdr.2018. 0109

An S, Yoon Y, Kothari S, Kothari N, Kim J, Lee E, Kim D, Park T, Smith G, Carbis R (2011) Physico-chemical properties of Salmonella Typhi Vi polysaccharide-diphtheria toxoid conjugate vaccines affect immunogenicity. Vaccine 29:7618-7623. https://doi.org/10. 1016/j.vaccine.2011.08.019

Anderson M, Sansonetti P, Marteyn B (2016) Shigella diversity and changing landscape: insights for the twenty-first century. Front Cell Infect Microbiol 6:45. https://doi.org/10.3389/fcimb.2016. 00045

Angelakopoulos H, Hohmann EL (2000) Pilot study of phoP/phoQdeleted Salmonella enterica serovar typhimurium expressing Helicobacter pylori urease in adult volunteers. Infect Immun 68: 2135-2141. https://doi.org/10.1128/iai.68.4.2135-2141.2000

Anish C, Schumann B, Pereira C, Seeberger P (2014) Chemical biology approaches to designing defined carbohydrate vaccines. Chem Biol 21:38-50. https://doi.org/10.1016/j.chembiol.2014.01.002

Arcuri M, Di Benedetto R, Cunningham AF, Saul A, MacLennan CA, Micoli F (2017) The influence of conjugation variables on the design and immunogenicity of a glycoconjugate vaccine against Salmonella Typhi. PLoS One 12(12):e0189100. https://doi.org/10. 1371/journal.pone. 0189100

Argimón S, Yeats, C, Goater R et al (2020) A global resource for genomic predictions of antimicrobial resistance and surveillance of Salmonella Typhi at Pathogenwatch. https://doi.org/10.1101/2020. 07.03.186692

Ashcroft M, Ritchie J, Nicholson C (1964) Controlled field trial in British Guiana school children of heat-killed-phenolized and acetone-killed lyophilized typhoid vaccines. Am J Epidemiol 79:196-206. https:// doi.org/10.1093/oxfordjournals.aje.a120376

Ashcroft M, Singh B, Nicholson C, Ritchie J, Sobryan E, Williams F (1967) A seven-year field trial of two typhoid vaccines in Guyana. Lancet 290:1056-1059. https://doi.org/10.1016/S0140-6736(67) 90335-2

Avci F, Berti F, Dull P, Hennessey J, Pavliak V, Prasad A, Vann W, Wacker M, Marcq M (2019) Glycoconjugates: what it would take to master these well-known yet little-understood immunogens for vaccine development. mSphere 4(5):e00520-e00519. https://doi. org/10.1128/mSphere.00520-19

Baliban S, Curtis B, Toema D, Tennant S, Levine M, Pasetti M, Simon R (2018) Immunogenicity and efficacy following sequential parenterally-administered doses of Salmonella Enteritidis COPS: FliC glycoconjugates in infant and adult mice. PLoS Negl Trop Dis 12:e006522. https://doi.org/10.1371/journal.pntd.0006522

Baliban S, Lu Y, Malley R (2020) Overview of the Nontyphoidal and Paratyphoidal Salmonella vaccine pipeline: current status and future prospects. Clin Infect Dis 71:S151-S154. https://doi.org/10.1093/ $\mathrm{cid} / \mathrm{ciaa} 514$

Bardotti A, Averani G, Berti F, Berti S, Carinci V, D’Ascenzi S, Fabbri B, Giannini S, Giannozzi A, Magagnoli C, Proietti D, Norelli F, Rappouli R, Ricci S, Costantino P (2008) Physicochemical characterisation of glycoconjugate vaccines for prevention of meningococcal diseases. Vaccine 26:2284-2296. https://doi.org/ 10.1016/j.vaccine.2008.01.022

Barel L, Mulard L (2019) Classical and novel strategies to develop a Shigella glycoconjugate vaccine: from concept to efficacy in human. Hum Vaccines Immunother 15:1338-1356. https://doi.org/10.1080/ 21645515.2019.1606972

Bayart C, Jean E, Paillagot M, Renoud A, Raillard A, Paladino J, Le Borgne M (2019) Comparison of SEC and AF4 analytical tools for size estimation of typhoid Vi polysaccharides. Anal Methods 11:4851-4858. https://doi.org/10.1039/c9ay00145j

Beresford NJ, Martino A, Feavers IM, Corbel MJ, Bai X, Borrow R, Bolgiano B (2017) Quality, immunogenicity and stability of meningococcal serogroups ACWY-CRM 197 , DT and TT glycoconjugate vaccines. Vaccine 35:3598-3606. https://doi.org/10.1016/j.vaccine. 2017.03.066

Beri S, Gandhi D, Ravenscroft N (2019) Use of NMR as an analytical tool in the process development of conjugate vaccines against Haemophilus influenzae type $\mathrm{b}$ (Hib) and meningococcal serogroup A (MenA). Biologicals 62:102-106. https://doi.org/10.1016/j. biologicals.2019.10.005

Berti F, Micoli F (2020) Improving efficacy of glycoconjugate vaccines: from chemical conjugates to next generation constructs. Curr Opin Immunol 65:42-49. https://doi.org/10.1016/j.coi.2020.03.015

Berti F, Ravenscroft N (2015) Characterization of carbohydrate vaccines by NMR spectroscopy. In: Lepenies B (ed) Carbohydrate-based vaccines: methods and protocols. Methods in Molecular Biology 1331. Human Press, New York, pp 189-209

Berti F, De Ricco R, Rappuoli R (2018) Role of O-acetylation in the immunogenicity of bacterial polysaccharide vaccines. Molecules 23:1340. https://doi.org/10.3390/molecules 23061340

Bhutta Z, Capeding M, Bavdekar A et al (2014) Immunogenicity and safety of the Vi-CRM197 conjugate vaccine against typhoid fever in adults, children, and infants in south and southeast Asia: results from two randomised, observer-blind, age de-escalation, phase 2 trials. Lancet Infect Dis 14:119-129. https://doi.org/10.1016/ s1473-3099(13)70241-x

Bolgiano B, Mawas F, Yost SE, Crane DT, Lemercinier X, Corbel MJ (2001) Effect of physico-chemical modification on the immunogenicity of Haemophilus influenzae type b oligosaccharide-CRM $\mathrm{C}_{197}$ conjugate vaccines. Vaccine 19:3189-3200. https://doi.org/10. 1016/s0264-410x(01)00024-x

Brunner K, Samassa F, Sansonetti P, Phalipon A (2019) Shigellamediated immunosuppression in the human gut: subversion extends from innate to adaptive immune responses. Hum Vaccines Immunother 15:1317-1325. https://doi.org/10.1080/21645515. 2019.1594132

Caboni M, Pédron T, Rossi O, Goulding D, Pickard D, Citiulo F, MacLennan CA, Dougan G, Thomson NR, Saul A, Sansonetti PJ, Gerke C (2015) An O antigen capsule modulates bacterial pathogenesis in Shigella sonnei. PLoS Pathog 11(3):e1004749. https:// doi.org/10.1371/journal.ppat.1004749

Carter J, Blondel C, Zaldívar M, Álvarez S, Marolda C, Valvano M, Contreras I (2007) O-antigen modal chain length in Shigella flexneri $2 \mathrm{a}$ is growth-regulated through $\mathrm{RfaH}-$ mediated transcriptional control of the wzy gene. Microbiol 153:3499-3507. https://doi.org/10. 1099/mic.0.2007/010066-0

Cohen D, Muhsen K (2019) Vaccines for enteric diseases. Hum Vaccines Immunother 15:1205-1214. https://doi.org/10.1080/21645515. 2019.1611200

Cohen D, Ashkenazi S, Green MS, Gdalevich M, Robin G, Slepon R, Yavzori M, Orr N, Block C, Ashkenazi I, Shemer J, Taylor DN, Hale TL, Sadoff JC, Pavliakova D, Schneerson R, Robbins JB (1997) Double-blind vaccine-controlled randomised efficacy trial of an investigational Shigella sonnei conjugate vaccine in young adults. Lancet 349:155-159. https://doi.org/10.1016/S01406736(96)06255-1 
Cohen D, Meron-Sudai S, Bialik A, Asato V, Goren S, Ariel-Cohen O, Reizis A, Hochberg A, Ashkenazi S (2019) Serum IgG antibodies to Shigella lipopolysaccharide antigens - a correlate of protection against shigellosis. Hum Vaccines Immunother 15:1401-1408. https://doi.org/10.1080/21645515.2019.1606971

Cordis.europa.eu (2020) CORDIS | European Commission. [online] Available at: https://cordis.europa.eu/article/id/421458-a-novelplatform-for-the-design-of-effective-vaccines-against-bacteria. Accessed 15 Aug 2020

Crane D, Bolgiano JC (1997) Comparison of the diphtheria mutant toxin, $\mathrm{CRM}_{197}$, with a Haemophilus influenzae type-b polysaccharide$\mathrm{CRM}_{197}$ conjugate by optical spectroscopy. Eur J Biochem 246(2):320-327. https://doi.org/10.1111/j.1432-1033.1997.00320.x

Crump J, Sjölund-Karlsson M, Gordon M, Parry C (2015) Epidemiology, clinical presentation, laboratory diagnosis, antimicrobial resistance, and antimicrobial management of invasive Salmonella infections. Clin Microbiol Rev 28:901-937. https://doi.org/10.1128/CMR. 00002-15

Das A, Mandal J (2019) Extensive inter-strain diversity among clinical isolates of Shigella flexneri with reference to its serotype, virulence traits and plasmid incompatibility types, a study from south India over a 6-year period. Gut Pathog 11(1). https://doi.org/10.1186/ s13099-019-0314-9

De Benedetto G, Alfini R, Cescutti P et al (2017a) Characterization of Oantigen delivered by generalized modules for membrane antigens (GMMA) vaccine candidates against nontyphoidal Salmonella. Vaccine 35:419-426. https://doi.org/10.1016/j.vaccine.2016.11.089

De Benedetto G, Cescutti P, Giannelli C, Rizzo R, Micoli F (2017b) Multiple techniques for size determination of generalized modules for membrane antigens from Salmonella typhimurium and Salmonella enteritidis. ACS Omega 2:8282-8289. https://doi.org/ 10.1021/acsomega.7b01173

Dharmasena MN, Osorio M, Filipova S, Marsh C, Stibitz S, Kopecko DJ (2016) Stable expression of Shigella dysenteriae serotype 1 Oantigen genes integrated into the chromosome of live Salmonella oral vaccine vector Ty21a. Pathogens Dis 74(8):ftw09. https://doi. org/10.1093/femspd/ftw098

Dische Z, Shettles LB (1948) A specific color reaction of methylpentoses and a spectrophotometric micromethod for their determination. J Biol Chem 175:595-603

Dubois M, Gilles K, Hamilton J, Rebers P, Smith F (1951) A colorimetric method for the determination of sugars. Nat 168:167-167. https:// doi.org/10.1038/168167a0

Emami P, Motevalian S, Pepin E, Zydney A (2018) Impact of module geometry on the ultrafiltration behavior of capsular polysaccharides for vaccines. J Membr Sci 561:19-25. https://doi.org/10.1016/j. memsci.2018.05.024

Gao F, Swann C, Rigsby P, Rijpkema S, Lockyer K, Logan A, Bolgiano B, Vi IS, Working Group (2019) Evaluation of two WHO First International Standards for Vi PS from Citrobacter freundii and Salmonella enterica subspecies enterica serovar Typhi. Biologicals 57:34 45. https://doi.org/10.1016/j.biologicals.2018.11.004

Gerke C, Colucci A, Giannelli C et al (2015) Production of a Shigella sonnei vaccine based on generalized modules for membrane antigens (GMMA), 1790GAHB. PLoS One 10(8):e0134478. https:// doi.org/10.1371/journal.pone.0134478

Giannelli C, Raso M, Palmieri E, De Felice A, Pippi F, Micoli F (2020) Development of a specific and sensitive HPAEC-PAD method for quantification of Vi polysaccharide applicable to other polysaccharides containing amino uronic acids. Anal Chem 92:6304-6311. https://doi.org/10.1021/acs.analchem.9b05107?ref=pdf

Giannelli C, Cappelletti E, Di Benedetto R, Pippi F, Arcuri M, Di Cioccio V, Martin LB, Saul A, Micoli F (2017) Determination of free polysaccharide in Vi glycoconjugate vaccine against typhoid fever. JPharm Biomed Anal 139:143-147
Giardina P, Longworth E, Evans-Johnson R et al (2005) Analysis of human serum immunoglobulin $\mathrm{G}$ against $\mathrm{O}$-acetyl-positive and $\mathrm{O}$ acetyl-negative serogroup W135 meningococcal capsular polysaccharide. Clin Diagn Lab Immunol 12:586-592. https://doi.org/10. 1128/CDLI.12.5.586-592.2005

Giuntini S, Balducci E, Cerofolini L, Ravera E, Fragai M, Berti F, Luchinat C (2017) Characterization of the conjugation pattern in large polysaccharide-protein conjugates by NMR spectroscopy. Angew Chem Int Ed 56:14997-15001. https://doi.org/10.1002/ anie. 201709274

Global Burden of Diseases 2019 Disease and Injuries Collaborators (2020) Global burden of 369 diseases and injuries in 204 countries and territories, 1990-2019: a systematic analysis for the Global Burden of Disease Study 2019. Lancet 396:1204-22. https://doi. org/10.1016/S0140-6736(20)30925-9 Accessed 2 Nov 2020

Global Burden of Diseases 2019 Risk Factor Collaborators (2020) Global burden of 87 risk factors in 204 countries and territories, 1990-2019: a systematic analysis for the Global Burden of Disease Study 2019. Lancet 396:1223-1249. https://doi.org/10.1016/S0140-6736(20) 30752-2 Accessed 2 Nov 2020

GSK (2018) Discontinuation of Typherix adult vaccine. https://au.gsk. com/en-au/media/press-releases/2018/discontinuation-of-typherixadult-vaccine/. Accessed 8 Aug 2020

Harding SE (1992) Sedimentation analysis of polysaccharides. In: Harding SE, Rowe AJ, Horton JC (eds) Analytical ultracentrifugation in biochemistry and polymer science. Royal Society of Chemistry, Cambridge, pp 495-516 www.nottingham.ac.uk/ncmh/ documents/papers/Paper96.pdf

Harding SE, Abdelhameed AS, Morris GA (2010) Molecular weight distribution evaluation of polysaccharides and glycoconjugates using analytical ultracentrifugation. Macromol Biosci 10:714-720. https://doi.org/10.1002/mabi.201000072

Harding SE, Abdelhameed AS, Morris GA, Adams G, Laloux O, Cerny L, Bonnier B, Duvivier P, Conrath K, Lenfant C (2012) Solution properties of capsular polysaccharides from Streptococcus pneumoniae. Carbohydr Polym 90:237-242. https://doi.org/10. 1016/j.carbpol.2012.05.030

Harding SE, Adams GG, Almutairi F, Alzahrani Q, Erten T, Kök MS, Gillis RB (2015) Ultracentrifuge methods for the analysis of polysaccharides, glycoconjugates, and lignins. Methods Enzymol 562: 391-439

Hestrin S (1949) The reaction of acetylcholine and other carboxylic acid derivatives with hydroxylamine, and its analytical application. J Biol Chem 180:249-261

Heyns K, Kiessling G (1967) Strukturaufklärung des Vi-antigens aus Citrobacter freundii (E. coli) 5396/38. Carbohydr Res 3(3):340 353. https://doi.org/10.1016/S0008-6215(00)82210-7

Hindle Z, Chatfield SN, Phillemore J, Bentley M, Johnson J et al (2002) Characterization of Salmonella enterica derivatives harboring defined aroC and Salmonella pathogenicity island 2 type III secretion system (ssaV) mutations by immunization of healthy volunteers. Infect Immun 70:3457-3467

Hitri K, Kuttel M, De Benedetto G et al (2019) O-acetylation of typhoid capsular polysaccharide confers polysaccharide rigidity and immunodominance by masking additional epitopes. Vaccine 37: 3866-3875. https://doi.org/10.1016/j.vaccine.2019.05.050

Hlozek J, Ravenscroft N, Kuttel MM (2020) Effects of glucosylation and O-acetylation on the conformation of Shigella flexneri serogroup 2 O-antigen vaccine targets. J Phys Chem B 124:2806-2814. https:// doi.org/10.1021/acs.jpcb.0c01595

Ho MM, Lemercinier X, Bolgiano B, Crane DT, Corbel MJ (2001) Conformational stability of the subunit components of meningococcal oligosaccharide C-CRM ${ }_{197}$ conjugate vaccines. Biotechnol Appl Biochem 33:91-98. https://doi.org/10.1042/BA20000078

Ho MM, Mawas F, Bolgiano B, Lemercinier X, Crane D, Huskisson R, Corbel (2002) Physico-chemical and immunological examination of 
the thermal stability of tetanus toxoid conjugate vaccines. Vaccine 20:3509-3522. https://doi.org/10.1016/S0264-410X(02)00342-0

Ho MM, Bolgiano B, Martino A, Kairo SK, Corbel MJ (2006) Preclinical laboratory evaluation of a bivalent Staphylococcus aureus saccharide exotoxin A protein conjugate vaccine. Hum Vaccines 2:89-98. https://doi.org/10.4161/hv.2755

Humphries R, Schuetz A (2015) Antimicrobial susceptibility testing of bacteria that cause gastroenteritis. Clin Lab Med 35:313-331. https://doi.org/10.1016/j.cll.2015.02.005

Jin C, Gibani MM, Moore M et al (2017) Efficacy and immunogenicity of a Vi-tetanus toxoid conjugate vaccine in the prevention of typhoid fever using a controlled human infection model of Salmonella typhi: a randomised controlled, phase $2 b$ trial. Lancet 390:2472-2480. https://doi.org/10.1016/S0140-6736(17)32149-9

Jones C, An S, Yoon Y, Kothari S, Sahastrabuddhe S, Carbis R (2020) Spectroscopic characterisation of a series of Salmonella Typhi Vidiphtheria toxoid glycoconjugate antigens differing in polysaccharide-protein ratio. J Pharm Biomed Anal 181:113100. https://doi.org/10.1016/j.jpba.2020.113100

Jumel K, Ho MM, Bolgiano B (2002) Evaluation of Meningococcal C oligosaccharide conjugate vaccines by size exclusion chromatography/multi-angle laser light scattering. Biotechnol Appl Biochem 36:219-226. https://doi.org/10.1042/BA20020066

Kaminski RW, Wu M, Turbyfill KR et al (2014) Development and preclinical evaluation of a trivalent, formalin-inactivated Shigella whole-cell vaccine. Clin Vaccine Immunol 21:366-382. https:// doi.org/10.1128/CVI.00683-13

Kämpf MM, Braun M, Sirena D et al (2015) In vivo production of a novel glycoconjugate vaccine against Shigella flexneri 2a in recombinant Escherichia coli: identification of stimulating factors for in vivo glycosylation. Microb Cell Factories 14:12. https://doi.org/10.1186/ s12934-015-0195-7

Kao G, Tsai C (2004) Quantification of O-acetyl, N-acetyl and phosphate groups and determination of the extent of $\mathrm{O}$-acetylation in bacterial vaccine polysaccharides by high-performance anion-exchange chromatography with conductivity detection (HPAEC-CD). Vaccine 22: 335-344. https://doi.org/10.1016/j.vaccine.2003.08.008

Khalil I, Troeger C, Blacker B et al (2018) Morbidity and mortality due to Shigella and enterotoxigenic Escherichia coli diarrhoea: The Global Burden of Disease Study 1990-2016. Lancet Infect Dis 18(11): 1229-1240. https://doi.org/10.1016/S1473-3099(18)30475-4

Khan M, Franco-Paredes C, Sahastrabuddhe S, Ochiai R, Mogasale V, Gessner B (2017) Barriers to typhoid fever vaccine access in endemic countries. Res Rep Trop Med 8:37-44. https://doi.org/10.2147/ RRTM.S97309

Kim MJ, Moon YH, Kim H et al (2018) Cross-protective Shigella wholecell vaccine with a truncated O-polysaccharide chain. Front Microbiol 9:2609. https://doi.org/10.3389/fmicb.2018.02609

Kis Z, Shattock R, Shah N, Kontoravdi C (2018) Emerging technologies for low-cost, rapid vaccine manufacture. Biotechnol J 14:1800376. https://doi.org/10.1002/biot.201800376

Klemm E, Shakoor S, Page A et al (2018) Emergence of an extensively drug-resistant Salmonella enterica serovar Typhi clone harboring a promiscuous plasmid encoding resistance to fluoroquinolones and third-generation cephalosporins. mBio 9(1). https://doi.org/10.1128/ mbio.00105-18

Knirel Y, Sun Q, Senchenkova S, Perepelov A, Shashkov A, Xu J (2015) O-Antigen modifications providing antigenic diversity of Shigella flexneri and underlying genetic mechanisms. Biochem Mosc 80: 901-914. https://doi.org/10.1134/S0006297915070093

Kothari N, Genschmer K, Kothari S, Kim J, Briles D, Rhee D, Carbis R (2014) Preparation and testing of a Vi conjugate vaccine using pneumococcal surface protein A (PspA) from Streptococcus pneumoniae as the carrier protein. Vaccine 32:5755-5760. https://doi.org/10. 1016/j.vaccine.2014.08.041
Kotloff K, Riddle M, Platts-Mills J, Pavlinac P, Zaidi A (2018) Shigellosis. Lancet 391:801-812. https://doi.org/10.1016/s01406736(17)33296-8

Kubler-Kielb J, Vinogradov E, Chu C, Schneerson R (2007) OAcetylation in the O-specific polysaccharide isolated from Shigella flexneri serotype 2a. Carbohydr Res 342:643-647. https://doi.org/ 10.1016/j.carres.2006.09.017

Lei QP, Lamb DH, Heller R, Pietrobon P (2000) Quantitation of low level unconjugated polysaccharide in tetanus-toxoid conjugate vaccine by HPAEC-PAD following rapid separation by deoxycholate/HCl. J Pharm Biomed Anal 21:1087-1091. https://doi.org/10.1016/ s0731-7085(99)00183-1

Lemercinier X, Martinez-Cabrera I, Jones C (2000) Use and validation of an NMR test for the identity and $\mathrm{O}$-acetyl content of the Salmonella Typhi Vi Capsular Polysaccharide Vaccine. Biologicals 28:17-24. https://doi.org/10.1006/biol.1999.0238

Leyva A, Quintana A, Sánchez M, Rodríguez E, Cremata J, Sánchez J (2008) Rapid and sensitive anthrone-sulfuric acid assay in microplate format to quantify carbohydrate in biopharmaceutical products: method development and validation. Biologicals 36(2):134 141. https://doi.org/10.1016/j.biologicals.2007.09.001

Lindberg A, Karnell A, Weintraub A (1991) The lipopolysaccharide of Shigella bacteria as a virulence factor. Clin Infect Dis 13(Supplement_4):S279-S284. https://doi.org/10.1093/clinids/13. supplement_4.s279

Liston SD, Ovchinnikova OG, Whitfield C (2016) Unique lipid anchor attaches Vi antigen capsule to the surface of Salmonella enterica serovar typhi. Proc Natl Acad Sci U S A 113:6719-6724. https:// doi.org/10.1073/pnas.1524665113

Liu B, Knirel YA, Feng L, Perepelov AV, Senchenkova SN, Wang Q, Reeves PR, Wang L (2008) Structure and genetics of Shigella O antigens. FEMS Microbiol Rev 32:627-653. https://doi.org/10. 1111/j.1574-6976.2008.00114.x

Liu J, Platts-Mills J, Juma J et al (2016) Use of quantitative molecular diagnostic methods to identify causes of diarrhoea in children: a reanalysis of the GEMS case-control study. Lancet 388:12911301. https://doi.org/10.1016/s0140-6736(16)31529-x

Livio S, Strockbine N, Panchalingam S et al (2014) Shigella isolates from the global enteric multicenter study inform vaccine development. Clin Infect Dis 59(7):933-941. https://doi.org/10.1093/cid\% 2 Fciu 468

Lockyer K, Gao F, Derrick JP, Bolgiano B (2015) Structural correlates of carrier protein recognition in tetanus toxoid conjugated bacterial protein vaccines. Vaccine 33:1345-1352. https://doi.org/10.1016/j. vaccine.2015.01.046

Lockyer K, Gao F, Francis RJ, Eastwood D, Khatri B, Stebbings R, Derrick JP, Bolgiano B (2020) Higher mass meningococcal group C-tetanus toxoid vaccines conjugated with carbodiimide correlate with greater immunogenicity. Vaccine 38:2859-2869. https://doi. org/10.1016/j.vaccine.2020.02.012

Lyodov VA, Aparin PG (2014) Clinical studies of the vaccine preparation for prevention of Flexner dysentery on the basis of modified Shigella flexneri lipopolysaccharide (based on the results of the I phase of clinical trials). Acta Biomed Sci (East Siberian Biomed J) 2014(4):91-95

MacCalman T, Phillips-Jones M, Harding S (2019) Glycoconjugate vaccines: some observations on carrier and production methods. Biotechnol Genet Eng Rev 35:93-125. https://doi.org/10.1080/ 02648725.2019.1703614

MacLennan C, Steele D (2019) Invasive non-typhoid Salmonella vaccines. WHO Product Development for Vaccines Advisory Committee 26-28 June 2019. https://www.who.int/immunization/ research/meetings workshops/13 Steele iNTS PDVAC 2019. pdf?ua=1. Accessed 22 Oct 2020 
MacLennan C, Martin L, Micoli F (2014) Vaccines against invasive Salmonella disease. Hum Vaccines Immunother 10:1478-1493. https://doi.org/10.4161/hv.29054

Mani S, Wierzba T, Walker R (2016) Status of vaccine research and development for Shigella. Vaccine 34:2887-2894. https://doi.org/ 10.1016/j.vaccine.2016.02.075

Martin L, Simon R, MacLennan C, Tennant S, Sahastrabuddhe S, Khan M (2016) Status of paratyphoid fever vaccine research and development. Vaccine 34:2900-2902. https://doi.org/10.1016/j.vaccine. 2016.03.106

Martinez-Becerra FJ, Chen X, Dickenson NE et al (2013) Characterization of a novel fusion protein from IpaB and IpaD of Shigella spp. and its potential as a pan-Shigella vaccine. Infect Immun 81:4470-4477. https://doi.org/10.1128/IAI.00859-13

Meloni E, Colucci AM, Micoli F, Sollai L, Gavini M, Saul A, Di Cioccio V, Calman AM (2015) Simplified low-cost production of O-antigen from Salmonella typhimurium generalized modules for membrane antigens (GMMA). J Biotechnol 198:46-52. https://doi.org/10. 1016/j.jbiotec.2015.01.020

Méndez Y, Chang J, Humpierre A et al (2018) Multicomponent polysaccharide-protein bioconjugation in the development of antibacterial glycoconjugate vaccine candidates. Chem Sci 9:25812588. https://doi.org/10.1039/C7SC05467J

Micoli F, Rondini S, Pisoni I, Proietti D, Berti F, Costantino P, Rappuoli R, Szu S, Saul A, Martin LB (2011) Vi-CRM 197 as a new conjugate vaccine against Salmonella Typhi. Vaccine 29:712-720. https://doi. org/10.1016/j.vaccine.2010.11.022

Micoli F, Rondini S, Gavini M et al (2013) A scalable method for Oantigen purification applied to various Salmonella serovars. Anal Biochem 434:136-145. https://doi.org/10.1016/j.ab.2012.10.038

Micoli F, Ravenscroft N, Cescutti P, Stefanetti G, Londero S, Rondini S, MacLennan C (2014) Structural analysis of O-polysaccharide chains extracted from different Salmonella strains. Carbohydr Res 385:1-8. https://doi.org/10.1016/j.carres.2013.12.003

Micoli F, Adamo R, Costantino P (2018a) Protein carriers for glycoconjugate vaccines: history selection criteria characterization and new trends. Mol 23:1451. https://doi.org/10.3390/ molecules 23061451

Micoli F, Costantino P, Adamo R (2018b) Potential targets for next generation antimicrobial glycoconjugate vaccines. FEMS Microbiol Rev 42(3):388-423. https://doi.org/10.1093/femsre/fuy011

Micoli F, Rondini S, Alfini R et al (2018c) Comparative immunogenicity and efficacy of equivalent outer membrane vesicle and glycoconjugate vaccines against nontyphoidal Salmonella. Proc Natl Acad Sci 115:10428-10433. https://doi.org/10.1073/pnas. 1807655115

Micoli F, Alfini R, Di Benedetto R, Necchi F, Schiavo F, Mancini F, Carducci M, Palmieri E, Balocchi C, Gasperini G, Brunelli B, Costantino P, Adamo R, Piccioli D, Saul A (2020a) GMMA is a versatile platform to design effective multivalent combination vaccines. Vaccines 8:540. https://doi.org/10.3390/vaccines8030540

Micoli F, Bjarnarson SP, Arcuri M, Aradottir Pind AA, Magnusdottir GJ, Necchi F, Di Benedetto R, Carducci M, Schiavo F, Giannelli C, Pisoni I, Martin LB, Del Giudice G, MacLennan CA, Rappuoli R, Jonsdottir I, Saul A (2020b) Short Vi-polysaccharide abrogates Tindependent immune response and hyporesponsiveness elicited by long Vi-CRM ${ }_{197}$ conjugate vaccine. Proc Natl Acad Sci U S A 117: 24443-24449. https://doi.org/10.1073/pnas.2005857117

Morona R, Daniels C, Van Den Bosch L (2003) Genetic modulation of Shigella flexneri 2 a lipopolysaccharide $\mathrm{O}$ antigen modal chain length reveals that it has been optimized for virulence. Microbiol 149(4):925-939. https://doi.org/10.1099/mic.0.26141-0

Mulard L (2017) Bacterial polysaccharides as major surface antigens: interest in O-acetyl substitutions. In Rauter AP, Lindhorst T, Queneau Y (eds) Carbohydr Chemistry:Chemical and biological approaches. Vol 43, Ed. AP Rauter, T Lindhorst, Y Queneau.
Roy Soc Chem, London. https://oi.org/10.1039/978178801064100071

Muthuirulandi Sethuvel D, Devanga Ragupathi N, Anandan S, Veeraraghavan B (2016) Update on: Shigella new serogroups/ serotypes and their antimicrobial resistance. Lett Appl Microbiol 64:8-18. https://doi.org/10.1111/lam.12690

NIBSC (2020) NIBSC to develop International Standards for Shigella and Group B Streptococcus. https://www.nibsc.org/about_us/ latest_news/shigella_gbs.aspx. Accessed 27 Sept 2020

NICE (2020) Summary of antimicrobial prescribing guidance - managing common Infections. https://www.nice.org.uk/Media/Default/ About/what-we-do/NICE-guidance/antimicrobial\%20guidance/ summary-antimicrobial-prescribing-guidance.pdf, Accessed 7 Aug 2020

Noyes A, Boesch A, Godavarti R, Titchener-Hooker R, Coffman J, Mukhopadhyay T (2013) High throughput quantification of capsular polysaccharides for multivalent vaccines using precipitation with a cationic surfactant. Vaccine 31:5659-5665. https://doi.org/10. 1016/j.vaccine.2013.09.075

Page M, MacLean D, Schudoma C (2016) blastjs: a BLAST+ wrapper for Node.js. BMC Res Notes 9(1). https://doi.org/10.1186/s13104-0161938-1

Palmieri E, Arato V, Oldrini D, Ricchetti B, Aruta MG, Pansegrau W, Marchi S, Giusti F, Ferlenghi I, Rossi O, Alfini R, Giannelli C, Gasperini G, Necchi F, Micoli F (2021) Stability of Outer Membrane Vesicles-Based Vaccines, Identifying the Most Appropriate Methods to Detect Changes in Vaccine Potency. Vaccines 9(3):229

Pastor Y, Camacho AI, Zúñiga-Ripa A, Merchán A, Rosas P, Irache JM, Gamazo C (2018) Towards a subunit vaccine from a Shigella flexneri $\Delta$ tolR mutant. Vaccine 36:7509-7519. https://doi.org/10. 1016/j.vaccine.2018.10.066

Perepelov A, Shekht M, Liu B, Shevelev S, Ledov V, Senchenkova S, L'vov V, Shashkov A, Feng L, Aparin P, Wang L, Knirel Y (2012) Shigella flexneri O-antigens revisited: final elucidation of the $\mathrm{O}$ acetylation profiles and a survey of the $\mathrm{O}$-antigen structure diversity. FEMS Immunol Med Microbiol 66:201-210

Puzari M, Sharma M, Chetia P (2018) Emergence of antibiotic resistant Shigella species: a matter of concern. J Infect Public Health 11:451454. https://doi.org/10.1016/j.jiph.2017.09.025

Qadri A, Ghosh S, Talwar G (1990) Monoclonal antibodies against two discrete determinants on Vi capsular polysaccharide. J Immunoass 11(2):235-250. https://doi.org/10.1080/01971529008053271

Rappuoli R, De Gregorio E, Costantino P (2018) On the mechanisms of conjugate vaccines. Proc Natl Acad Sci 116:14-16. https://doi.org/ 10.1073/pnas. 1819612116

Raso M, Gasperini G, Alfini R et al (2020) GMMA and glycoconjugate approaches compared in mice for the development of a vaccine against Shigella flexneri serotype 6. Vaccines 8:160. https://oi. org $/ 10.3390 /$ vaccines 8020160

Ravenscroft N, Cescutti P, Gavini M, Stefanetti G, MacLennan CA, Martin LB, Micoli F (2015a) Structural analysis of the Oacetylated O-polysaccharide isolated from Salmonella Paratyphi A and used for vaccine preparation. Carbohydr Res 404:108-116. https://doi.org/10.1016/j.carres.2014.12.002

Ravenscroft N, Costantino P, Talaga P et al (2015b) Glycoconjugate vaccines. In: Nunnally BK, Sitrin RD, Turula VE (eds) Vaccine analysis: strategies, principles, and control. Springer-Verlag, Berlin Heidelberg, pp 301-381. https://doi.org/10.1007/978-3-662-4502468

Ravenscroft N, Haeuptle M, Kowarik M et al (2016) Purification and characterization of a Shigella conjugate vaccine produced by glycoengineering Escherichia coli. Glycobiology 26(1):51-62. https://doi.org/10.1093/glycob/cwv077

Reddy EA, Shaw AV, Crump JA (2010) Community-acquired bloodstream infections in Africa: a systematic review and meta-analysis. 
Lancet Infect Dis 10:417-432. https://doi.org/10.1016/S14733099(10)70072-4

Riddle M, Chen W, Kirkwood C, MacLennan C (2018) Update on vaccines for enteric pathogens. Clin Microbiol Infect 24(10):10391045. https://doi.org/10.1016/j.cmi.2018.06.023

Rigsby P, Beamish E, Hockley J et al (2020) Evaluation of a standardised Vi poly-1-lysine ELISA for serology of Vi capsular polysaccharide antibodies. Biologicals 66:21-29. https://doi.org/10.1016/j. biologicals.2020.05.002

Rijpkema S, Hockley J, Logan A et al (2018) Establishment of the first International Standard for human anti-typhoid capsular Vi polysaccharide IgG. Biologicals 56:29-38. https://doi.org/10.1016/j. biologicals.2018.09.001

Robbins J, Robbins J (1984) Reexamination of the protective role of the capsular polysaccharide (Vi antigen) of Salmonella typhi. J Infect Dis 150:436-449. https://doi.org/10.1093/infdis/150.3.436

Rohrer JS (2020) Vaccine quality ensured by high-performance anionexchange chromatography with pulsed amperometric detection. SLAS Technol 25(4):320-328. https://doi.org/10.1177/ 2472630319890309

Rosminzdrav (2020) Gosudarstvenniy Reestr Lekarstvennih Sredstv. Registered Clinical Study №161 (04.04.2019) http://grls. rosminzdrav.ru/CIPermissionMini.aspx?CIStatementGUID= 23eee6a9-9c4e-47e2-992d-1 ed6d781013a\&CIPermGUID = CB5A344B-8A5B-4E1B-BB07-24C8D3ADCA68 . Accessed 29 Oct 2020

Rossi O, Pesce I, Giannelli C, Aprea S, Caboni M, Citiulo F, Valentini S, Ferlenghi I, MacLennan CA, D'Oro U, Saul A, Gerke C (2014) Modulation of endotoxicity of Shigella generalized modules for membrane antigens (GMMA) by genetic lipid A modifications: relative activation of TLR 4 and TLR 2 pathways in different mutants. J Biol Chem 289(36):24922-24935. https://doi.org/10.1074/jbc. m114.566570

Safari D, Marradi M, Chiodo F, Th Dekker H, Shan Y, Adamo R, Oscarson S, Rijkers G, Lahmann M, Kamerling J, Penadés S, Snippe H (2012) Gold nanoparticles as carriers for a synthetic Streptococcus pneumoniaetype 14 conjugate vaccine. Nanomedicine 7:651-662. https://doi.org/10.2217/nnm.11.151

Sahastrabuddhe S, Saluja T (2019) Overview of the typhoid conjugate vaccine pipeline: current status and future plans. Clin Infect Dis 68(Supplement_1):S22-S26. https://doi.org/10.1093/cid/ciy884

Salman M, St Michael F, Ali A, Jabbar A, Cairns C, Hayes AC, Rahman M, Iqbal M, Haque A, Cox AD (2017) First characterization of immunogenic conjugates of Vi negative Salmonella Typhi Ospecific polysaccharides with rEPA protein for vaccine development. J Immunol Methods 450:27-33. https://doi.org/10.1016/j. jim.2017.07.005

Serum Institute of India (2013) A novel quantification method for vaccines. Patent application. WO2013046226A3

Shane A, Mody R, Crump J et al (2017) 2017 Infectious Diseases Society of America Clinical Practice Guidelines for the Diagnosis and Management of Infectious Diarrhea. Clin Infect Dis 65:19631973. https://doi.org/10.1093/cid/cix959

Stanaway J, Reiner R, Blacker B et al (2019) The global burden of typhoid and paratyphoid fevers: a systematic analysis for the Global Burden of Disease Study 2017. Lancet Infect Dis 19:369381. https://doi.org/10.1016/S1473-3099(18)30685-6

Steele AD, Carey ME, Kumar S, MacLennan CA, Ma LF, Diaz Z, Zaidi AKM (2020) Typhoid conjugate vaccines and enteric fever control: where to next? Clin Infect Dis 71(Supplement_2):S185-S190. https://doi.org/10.1093/cid/ciaa343

Stone AL, Szu SC (1988) Application of optical properties of the Vi capsular polysaccharide for quantitation of the Vi antigen in vaccines for typhoid fever. J Clin Microbiol 26:719-725

Stromberg L, Mendez H, Mukundan H (2017) Detection methods for lipopolysaccharides: past and present. In: Escherichia coli - recent advances on physiology, pathogenesis and biotechnological applications. InTech, pp 141-168. https://doi.org/10.5772/intechopen. 68311

Sun X, Stefanetti G, Berti F, Kasper D (2018) Polysaccharide structure dictates mechanism of adaptive immune response to glycoconjugate vaccines. Proc Natl Acad Sci 116:193-198. https://doi.org/10.1073/ pnas. 1816401115

Syed K, Saluja T, Cho H et al (2020) Review on the recent advances on typhoid vaccine development and challenges ahead. Clin Infect Dis 71(Supplement 2):S141-S150. https://doi.org/10.1093/cid/ciaa504

Szu S, Li X, Stone A, Robbins J (1991) Relation between structure and immunologic properties of the Vi capsular polysaccharide. Infect Immun 59:4555-4561

Thiem V, Lin F, Canh D et al (2011) The Vi conjugate typhoid vaccine is safe elicits protective levels of IgG anti-Vi and is compatible with routine infant vaccines. Clin Vaccine Immunol 18:730-735. https:// doi.org/10.1128/cvi.00532-10

Thompson CN, Duy PT, Baker S (2015) The rising dominance of Shigella sonnei: an intercontinental shift in the etiology of bacillary dysentery. PLoS Negl Trop Dis 9(6):e0003708. https://doi.org/10. 1371/journal.pntd.0003708

Toapanta FR, Bernal PJ, Kotloff KL et al (2018) T cell mediated immunity induced by the live-attenuated Shigella flexneri 2 a vaccine candidate CVD 1208S in humans. J Transl Med 16:61. https://doi.org/ 10.1186/s12967-018-1439-1

Tribble D (2017) Resistant pathogens as causes of traveller's diarrhea globally and impact(s) on treatment failure and recommendations. J Travel Med 24(suppl_1):S6-S12. https://doi.org/10.1093/jtm/ taw090

Troeger C, Blacker B, Khalil I et al (2018) Estimates of the global regional and national morbidity mortality and aetiologies of diarrhoea in 195 countries: a systematic analysis for the Global Burden of Disease Study 2016. Lancet Infect Dis 18:1211-1228. https://doi. org/10.1016/S1473-3099(18)30362-1

United States Pharmacopeial Convention (2018) Nuclear magnetic resonance spectroscopy: identity testing of bacterial polysaccharides used in vaccine manufacturing. Chapter 198

Wang BZ (2003) Current status and development trend of dysentery vaccine. Progress in Microbiology and Immunology 4:54-59

Wen L, Edmunds G, Gibbons C, Zhang J, Gadi MR, Zhu H, Fang J, Liu X, Kong Y, Wang PG (2018) Toward Automated Enzymatic Synthesis of Oligosaccharides. Chem Rev 118(17):8151-8187

Wessels M, Paoletti L, Guttormsen H, Michon F, D'Ambra A, Kasper D (1998) Structural properties of group b Streptococcal type III polysaccharide conjugate vaccines that influence immunogenicity and efficacy. Infect Immun 66:2186-2192

West N (2005) Optimization of virulence functions through glucosylation of Shigella LPS. Science 307:1313-1317

Whitfield C, Williams DM, Kelly SD (2020) Lipopolysaccharide O-antigens: bacterial glycans made to measure. J Biol Chem 295:1059310609. https://doi.org/10.10741/jbc.REV120.009402

WHO (2005) Guidelines for the control of shigellosis including epidemics due to Shigella dysenteriae type 1. Geneva, World Health Organization. http://apps.who.int/iris/bitstream/10665/43252/1/ 924159330X.pdf?ua=1\&ua=1. Accessed 3 Aug 2020

WHO (2010) WHO recommendations on the management of diarrhoea and pneumonia in HIV infected infants and children. Geneva, World Health Organization. https://apps.who.int/iris/bitstream/handle/ 10665/44471/9789241548083_eng.pdf?sequence=1. Accessed 20 Oct 2020

WHO (2013) Pocket Book Of Hospital Care For Children. Geneva, World Health Organization. https://apps.who.int/iris/bitstream/ handle/10665/81170/9789241548373 eng.pdf?sequence $=1$. Accessed 20 Oct 2020

WHO. (2014a) Antimicrobial resistance global report on surveillance. Geneva, World Health Organization. http://apps.who.int/iris/ 
bitstream/10665/112642/1/9789241564748_eng.pdf. Accessed 3 Aug 2020

WHO (2014b) Guidelines on the quality, safety and efficacy of typhoid conjugate vaccines. Geneva, World Health Organization, WHO Tech Rep Ser. 987, Annex 3. https://www.who.int/biologicals/ areas/vaccines/TRS_987_Annex3.pdf?ua=1. Accessed 13 Aug 2020

WHO (2017a) Background paper to SAGE on typhoid vaccine policy recommendations. Geneva, World Health Organization. https:// www.who.int/immunization/sage/meetings/2017/october/1 Typhoid_SAGE_background_paper_Final_v3B.pdf?ua=1, accessed 05 Nov 2020

WHO (2017b) Evaluation of candidate international standards for Vi polysaccharide from citrobacter freundii and salmonella enterica subspecies enterica serovar Typhi. Geneva, World Health Organization, WHO/BS/2017.2310. https://www.who.int/ biologicals/expert_committee/BS.2017.2310_Vi_PS_Report_for_ WHO_Final.pdf. Accessed 3 Aug 2020

WHO (2017c) The selection and use of essential medicines. Geneva, World Health Organization, WHO Technical Report Series 1006 https://apps.who.int/iris/bitstream/handle/10665/259481/ 9789241210157-eng.pdf. Accessed 15 Aug 2020

WHO (2018) Global antimicrobial resistance surveillance system (GLASS) Report. Geneva, World Health Organization. https:// apps.who.int/iris/bitstream/handle/10665/259744/9789241513449eng.pdf? sequence $=1$. Accessed 20 Oct 2020

WHO (2020a) Draft WHO preferred product characteristics for vaccines against Shigella. Geneva, World Health Organization. https://www.
who.int/immunization/research/ppc-tpp/PPC_Shigella_draft_for review_april2020.pdf?ua=1. Accessed 14 Aug 2020

WHO (2020b) Recommendations to assume the quality, safety and efficacy of typhoid conjugate vaccines. Replacement of WHO Technical Report Series, No. 987, Annex 3. Geneva, World Health Organization. https://www.who.int/publications/m/item/ tcv71-recommendations

Williams P and Berkley J (2016) Dysentery (shigellosis) current who guidelines and the WHO essential medicine list for children. https://www.who.int/selection_medicines/committees/expert/21/ applications/s6_paed_antibiotics_appendix5_dysentery.pdf?ua $=1$. Accessed 12 Aug 2020

Williams P, Berkley J (2018) Guidelines for the treatment of dysentery (shigellosis): a systematic review of the evidence. Paediatr Int Child Health 38(sup1):S50-S65

Xu Q, Abeygunawardana C, Ng A, Sturgess A, Harmon B, Hennessey J (2005) Characterization and quantification of C-polysaccharide in Streptococcus pneumoniae capsular polysaccharide preparations. Anal Biochem 336:262-272

Yu H, An Y, Battistel M, Cipollo J, Freedberg D (2018) Improving analytical characterization of glycoconjugate vaccines through combined high-resolution MS and NMR: Application to Neisseria meningitidis serogroup B oligosaccharide-peptide glycoconjugates. Anal Chem 90:5040-5047

Publisher's note Springer Nature remains neutral with regard to jurisdictional claims in published maps and institutional affiliations. 